

\section{DISCLAIMER}

This report was prepared as an account of work sponsored by an agency of the United States Government. Neither the United States Government nor any agency Thereof, nor any of their employees, makes any warranty, express or implied, or assumes any legal liability or responsibility for the accuracy, completeness, or usefulness of any information, apparatus, product, or process disclosed, or represents that its use would not infringe privately owned rights. Reference herein to any specific commercial product, process, or service by trade name, trademark, manufacturer, or otherwise does not necessarily constitute or imply its endorsement, recommendation, or favoring by the United States Government or any agency thereof. The views and opinions of authors expressed herein do not necessarily state or reflect those of the United States Government or any agency thereof. 


\section{DISCLAIMER}

Portions of this document may be illegible in electronic image products. Images are produced from the best available original document. 


\title{
IODINE AND CESIUM IN OXIDE FUEL PELLETS AND ZIRCALOY-4 CLADDING OF IRRADIATED FUEL RODS (LWBR Development Program)
}

\author{
D. M. Ivak
}

L. A. Waldman

Contract No. EY-76-C-11-0014

March 1979

\section{Printed in the United States of America \\ Available from the \\ National Technical Information Service \\ U.S. Department of Commerce \\ 5285 Port Royal Road \\ Springfield, Virginia 22151}

NOTE This report was prepared as an accousit of work
sponsored by the United States Government. Neither the
United States nor the United States Department of
Energy, nor any of their employees, nor any of their
consractors, subcontractors, or their employees, makes
any warranty, express or implied, or assumes any legal
liability or responsibility for the accuracy, completenets
or usefulness of any information, apparatus, product or
process disclosed, or represents that its use would not
infringe privglely owned rights.

This document is an interim memorandum prepared primarily for internal reference and does not represent a final expression of the opinion of Westinghouse. When this memorandum is distributed externally, it is with the express understanding that Westinghouse makes no representation as to completeness, accuracy, or usability of information contained therein.

\section{BETTIS ATOMIC POWER LABORATORY WEST MIFFLIN, PENNSYLVANIA}

Operated fór the U. S. Department of Energy by WESTINGHOUSE ELECTRIC CORPORATION 


\section{NOTICE}

This report was prepared as an account of work sponsored by the United States Government. Neither the United States, nor the United States Department of Energy, nor any of their employees, nor any of their contractors, subcontractors, or their employees, makes any warranty, express or implied, or assumes any legal liability or responsibility for the accuracy, completeness or usefulness of any information, apparatus, product or process disclosed, or represents that its use would not infringe privately owned rights. 


\section{FOREWORD}

The Shippingport Atomic Power Station located in Shippingport, Pennsylvania was the first largescale, central-station nuclear power plant in the United States and the first plant of such size in the world operated solely to produce electric power. This program was started in 1953 to confirm the practical application of nuclear power for large-scale electric power generation. It has provided much of the technology being used for design and operation of the commercial, central-station nuclear power plants now in use.

Subsequent to development and successful operation of the Pressurized Water Reactor in the DOEowned reactor plant at the Shippingport Atomic Power Station, the Atomic. Energy Commision in 1965 undertook a research and development program to design and build a Light Water Breeder Reactor core for operation in the Shippingport Station.

The objective of the Light Water Breeder Reactor (LWBR) program has been to develop a technology that would significantly improve the utilization of the nation's nuclear fuel resources employing the well-established water reactor technology. To achieve this objective, work has been directed toward analysis, design, component tests, and fabrication of a water-cooled, thorium oxide fuel cycle breeder reactor for installation and operation at the Shippingport Station. The LWBR core started operation in the Shippingport Station in the Fall of 1977 and is expected to be operated for about 3 to 4 years. At the end of this period, the core will be removed and the spent fuel shipped to the Naval Reactors Expended Core Facility for a detailed examination to verify core performance including an evaluation of breeding characteristics.

In 1976, with fabrication of the Shippingport LWBR core nearing completion, the Energy Research and Development Administration established the Advanced Water Breeder Applications (AWBA) program to develop and disseminate technical information which would assist $U$. S. industry in evaluating the LWBR concept for commercial-scale applications. The program will explore some of the problems that would be faced by industry in adapting technology confirmed in the LWBR program. Information to be developed includes concepts for commercial-scale prebreeder cores which would produce uranium-233 for light water breeder cores while producing electric power, improvements for breeder cores based on the technology developed to fabricate and operate the Shippingport LWBR core, and other information and technology to aid in evaluating commercial-scale application of the LWBR concept.

All three development programs (Pressurized Water Reactor, Light Water Breeder Reactor, and Advanced Water Breeder Applications) have been administered by the Division of Naval Reactors with the goal of developing practical improvements in the utilization of nuclear fuel resources for generation of electrical energy using water-cooled nuclear reactors.

Technical information developed under the Shippingport. LWBR, and AWBA programs has been and will continue to be published in technical memoranda, one of which is this present report. 


\begin{abstract}
I. INTRODUCTION
II. PROBLEM HISTORY AND DESCRIPTION

III. EXPERIMENTAL PROCEDURE

IV. ANALYTICAL MODEL FOR THE PREDICTION OF IODINE CONCENTRATION

V. SUMMARY OF RESULTS

A. Radiochemical Analysis

B. Electron Microprobe Evaluation

1. 79-506

2. $79-442$

3. $79-478$

4. $79-576$

VI. DISCUSSION

$A$. Iodine Concentration in the Fuel Pellet

B. Iodine Concentration Associated with Zircaloy Cladding

C. Electron Microprobe Evaluation

VII. CONCLUSION

ACKNOWLEDGEMENTS

APPENDIX A-CLAD SLITTING FOR THE PREPARATION OF IODINE/CESIUM SAMPLES

APPENDIX B-RADIOCHEMICAL DETERMINATION OF IODINE AND CESIUM IN THE THORIA-URANIA FUEL RODS

APPENDIX C-ELECTRON MICROPROBE ANALYSIS OF IRRADIATED ZIRCALOY CLADDING SPECIMENS
\end{abstract}

\title{
LIST OF TABLES
}

Tablo Title

I Long-Lived Iodine Yield

II Iodine and Cesium Data Summary

III Summary of Measured Pellet Iodine as a Percentage of the Theoretical Amount Produced

IV Measured Cladding Iodine versus Calculated Cladding Iodine

C-1 Summary of Iodine and Cesium Measurements

C-2 Qualitative Analysis of 79-506

C- 13

C-3 Qualitative Analysis of 79-442, 79-478, 79-576

C. 14 


\section{LIST OF CHARTS}

B-1 Process Flow Diagram (Iodine and Cesium Determination)

C-1 Rod 79-506; End A; I, Cs Profile

C-15/C-16

C-2 Rod 79-506; End A; U, Te Profile

C- $15 / C-16$

C-3 Rod 79.506; End A; Cd, Th Profile

C-17/C-18

C-4 Rod 79-506; End B; I, Cs Profile

C- $17 / C-18$

C-5 Rod 79-506; End B; U, Te Profile

C- $19 / C-20$

C-6 Rod 79-506; End B; Cd, Th Profile

C- $19 / \mathrm{C}-20$

C-7 Rod 79-506; End A; Hg, I Profile

C-21/C-22

C 8

Rod 79-506; End A; Hg, Cs Profile

C-21/C. 22

\section{LIST OF FIGURES}

Figure

1

2

3

A-1 Cladding Slitter

Title

Comparison of Iodine Found by Clad Rinse and Dissolution to Iodine Calcu'lated with Model Using Measured Gas Release

Comparison of lodine Found by Clad Rinse and Dissolution to Iodine Calculated with Model Using Best Estimate Fission Gas Release

Comparison of Cladding Iodine Concentration: Upper Limit Basis Prediction versus Measured Values

C-1 Sample 79-442-4-K1, Slit Clad Retainer Section

A-2

C-7

C-2

C-3

C-4

C-5

Sample 79-478-1-2C-K1, Slit Clad Retainer Section

C-8

Sample 79-576-A $11-K 1$, Slit Clad Retainer Section

C- 9

Sample 79-506-A 1C-K1, Slit Clad Retainer Section

C- 10

Approximate Areas of Wavelength Scans

C-11 
Measurements of fission product iodine and cesium are reported for thoria and binary $\left(\mathrm{ThO}_{2}-\mathrm{UO}_{2}\right)$ fuels with various irradiation histories. These volatile fission products were measured on the cladding surface or in the fuel by using specially developed radiochemical techniques. The radiochemical iodine measurements are found to be in general agreement with a theoretical iodine release model for irradiated fuel. Microprobe examinations of irradiated fuel rod cladding sections show fission product cesium to be located preferentially at the pellet to pellet interface region. Fission product iodine was detected in the, interface region of one sample but generally remained below the microprobe limit of detection.

\title{
IODINE AND CESIUM IN OXIDE FUEL PELLETS
} AND ZIRCALOY - 4 CLADDING OF IRRADIATED FUEL RODS (LWBR Development Program)

\author{
D. M. Ivak \\ L. A. Waldman
}

\section{INTRODUCTION}

In general, pellet-cladding interaction failures of power reactor fuel rods have been attributed to stress corrosion cracking (SCC) (References l through 3). Although no specific corrosive agent has been positively identified as the cause of SCC failure in irradiated rods, several agents are major suspects. Fission product iodine has long been regarded as the most likely corrosive agent. The stress corrosion cracking of Zircaloy in iodine environments has been studied by a variety of investigators, among them, Wood" (Reference 4), Weinberg (Reference 5), Busby (Reference 6); Tucker (Reference 7), and Kreyns (Reference 8). A major study of stress corrosion cracking in power reactor fuel rods is reported in Reference 9.

Iodine is particularly suspect as a stress corrosion agent in fuel rods. Out-of-pile experiments hàve shown that Zircaloy tubing can develop cracks at stresses well below yield at cladding temperatures typical of operating reactors (680-750F) and for concentrations on the tubing inside surface in the range of $0.5-4 \mathrm{mg} / \mathrm{dm}^{2}$ of iodine (Reference 10 ).

Other corrosive agents have also been shown to affect stress corrosion resistance of Zircaloy tubing. References 1 and 11 provide concise reviews of the environmental agents which induce cracking in Zircaloy. In addition to iodine, two potential agents of interest are cesium and cadmium. References 4 and 12 report that the cesium attack of Zircaloy is confined to a narrow temperature band in the presence of water vapor and, in some cases, occurs only in the absence of $\mathrm{ZrO}_{2}$ film on the inside cladding surface.

Cadmium has been shown (Reference 9) to embrittle Zircaloy in out-of-pile experiments. Cadmium in combination with cesium significantly decreases the ductility of Zircaloy-2 (Reference 12).

As a consequence of the concern for the SCC of Zircaloy, a program was carried out to measure concentrations of cesium and iodine associated with oxide fuels and Zircaloy cladding. The program selected certain fuel rods irradiated as part of the LWBR fuel element development program. This report presents the results of the measurements on these test fuel rods and provides a description of a calculational model predicting iodine concentration in power reactor fuel rods containing $\mathrm{ThO}_{2}-\mathrm{UO}_{2}$.

\section{PROBLEM HISTORY AND DESCRIPTION}

Measurements of volatile fission products in irradiated fuel elements have been widely reported in the literature. Data have been obtained either by dissolving the irradiated material and analyzing for the particular fission product or by measuring the release of volatile fission products subsequent to post-irradiation annealing. 
In the category of the dissolution of nuclear fuels, the condition of fission product iodine in uranium metal was studied by Walton, Bowles, and Croall (Reference 13). In this investigation the uranium fuel was ground into a fine powder and fission product iodine extracted with hexane solution.

In the most widely used method of preparation, the fuel samples are first dissolved in nitric acid. Unless the fission product iodine remains in a high oxidation state, it may volatilize and some portion may be lost due to vaporization. For example, in Reference 14, Geithoff and Schneider report that as much as 30 percent of the fission iodine may volatilize during dissolution in nitric acid. To retain the iodine in solution, an additive can be used; the additive ( $\mathrm{HCl}$ ) retains the iodine in an oxidized. nonextractable form such as $\mathrm{IO}_{4}^{-}$(discussed in Reference 14). The quantitive determination of the iodine can be made either by precipitating the iodine from solution as silver iodide (Reference 13) or by liquid scintillation counting of a fixed iodine solution (Reference 15).

Volatile fission products have also been investigated by heating irradiated fuels in a closed system, driving off the volatile gases. Castleman and Tang used this technique to study the chemical nature of iodine and cesium by vaporizing in helium, irradiated uranium -3.5 percent molybdenum (Reference 16). Once released from the fuels, volatile products can be trapped downstream in condensers. bubblers or charcoal traps. The advantage of this volatile measurement technique over the dissolution is two-fold. First, volatile release can be studied as a function of tem perature. Second, no iodine is lost due to volatilization; it remains trapped somewhere within the closed system although some may be adsorbed on glassware.

Since the measurement of volatile fission products in test fuel rods was undertaken primarily because of concern related to stress corrosion cracking of Zircaloy cladding, particular emphasis was placed on the measurement of long-lived fission product iodine. The severity of an iodine stress corrosion environment has been shown to be a function of its concentration (up to $4 \mathrm{mg} / \mathrm{dm}^{2}$ ) on the surface of the cladding (References 7,8 , and 10). The primary objective was to measure the long-lived iodine that was associated with the Zircaloy cladding in irradiated rods and compare the measurements to a calculational model (presented in Section IV) for iodine release.

The particular problems associated with the measurement of fission product iodine present on the cladding surface are:

1. The volatility of iodine. As shown by previous investigators, free iodine may be lost from open systems due to its extreme volatility. A totally closed system of analysis was not considered practical for an irradiated rod because of its size and high activity.

2. Small amounts of material. Since the uranium-235 or uranium-233 fission yields of long-lived iodine are small (about 1-2 atoms per 100 fission events), only small amounts of iodine are produced. Typical irradiated test fuel pellets theoretically produce about 1 milligram of iodine- 129 for a burnup of $30,000 \mathrm{MWD} / \mathrm{T}$. If the iodine released is assumed to be about 10 percent of the total yield, then only about $1 \mathrm{mg} / \mathrm{dm}^{2}$ of iodine would be associated with the cladding.

3. The potential radiological hazard of irradiated specimens requires at least some of the procedure to be performed in a remote, shielded environment.

\section{EXPERIMENTAL PROCEDURE}

The determination of volatile fission products in irradiated test rods was performed using two methods: analytical radiochemistry and electron microprobe analysis.

The radiochemical techniques used to determine the long-lived iodine and cesium compounds are similar. First, samples were prepared from the irradiated rod by removing the appropriate axial cladding section of the rod (at or near the peak power location) and slitting the cladding segment to remove the fuel. The average sample size was a clad segment 2 to 4 inches in length and from $1 / 3$ to $1 / 2$ of the circumferential arc. The clad-slitting technique used to separate fuel and cladding was specifically developed to provide a minimum of damage to either component. A detailed description of the slitting operation is presented in Appendix A. 
The analytical procedure for iodine determination using cladding rinsing, cladding dissolution, or fuel pellet dissolution is essentially the same. In each application, a sample is rinsed with dilute acid, to which iodine carrier is later added, or dissolved in a solution containing a known amount of carrier iodine. The solution is treated with a series of oxidation/reduction reactions to cycle the carrier through the various oxidation states to assure isotopic exchange between the carrier and iodine-129. Separation from other fission products is performed in successive aqueous/organic extraction steps. Aliquots of the solution are then removed, and iodine-129 is determined by liquid scintillation spectrometry. The remainder of the solution is then treated with silver nitrate $\left(\mathrm{AgNO}_{3}\right)$. The iodine is precipitated out of solution in the form of silver iodide (AgI) which is used to determine the iodine recovery (chemical yield). The iodine-129 analysis is adjusted proportionally using the measured ratio of carrier yield. ${ }^{1}$ Finally, the adjusted iodine- 129 value is further corrected for total long-lived isotopes by adding the contribution of iodine-129 (calculated from published fission yields, Reference 17). The detailed analytical procedure for iodine determination in fuel pellets and cladding is presented in Appendix B.

Cesium concentration in the cladding was also measured from the same rinse and dissolution solutions prepared for iodine determination. The final determination of cesium is made by counting an aliquot of the solution for the barium-137m daughter of cesium-137 using gamma spectrometry. The detailed procedure for the determination of cesium in the cladding is presented in Appendix B.

In addition to the radiochemical technique employed for the determination of iodine and cesium, an electron microprobe examination of selected specimens was performed. Slit cladding samples were examined by electron microprobe for the presence and distribution on the ID cladding surface of volatile fission products. A detailed discussion of the electron microprobe investigation is contained in Appendix C.

\section{ANALYTICAL MODEL FOR THE PREDICTION OF IODINE CONCEN- TRATION}

The following method was used to calculate the iodine concentration in irradiated fuel rods. The cummulative iodine fission yields were obtained from References 18 and 19. Only the long-lived isotopes are of interest in this study due to the length of time between irradiation and examination. These long-lived isotopes account for most of the iodine produced at longer depletions. The long-lived isotopic iodine yields for uranium-233 and uranium-235 are contained in Table I. These yields have been combined and translated into weight yields using the molecular weights and Avogadro's number. This total weight yield in units of $\mathrm{gm} /$ fission event is also listed in Table I. (It should be noted that the total long-lived iodine weight yield for uranium-233 fissioning is about twice that of uranium-235.)

When these iodine weight yields were compared to the total isotopic iodine calculated using the CINDER codes (Reference 20), it was found that the total contribution of neutron absorption and beta decay was small when compared to isotopic fission yield. Furthermore, since the fission yields in Table I were always greater than the iodine yields obtained in dynamic equilibrium, these yields would provide additional conservatism to design calculations.

The formula used to calculate the long-lived iodine concentration is

$$
\mathrm{I}_{2}=\mathrm{YDR} \mathrm{V}_{\mathrm{f}} / 2 A_{\mathrm{c}}
$$

where

$\mathrm{Y}=$ the weight yield for long-lived isotopes from either uranium-235 or uranium-233, whichever is appropriate, in $\mathrm{mg} /$ fission (given in Table I)

$V_{1}=$ the volume of fuel in $\mathrm{cm}^{3}$

\footnotetext{
'For example, if the carrier yield is determined to be 50 percent, the sample iodine will be multiplied by a factor of 2.
} 
$A_{c}=$ the clad surface area in $\mathrm{dm}^{2}$

$D=$ the rod-average fuel depletion (per compartment volume) in fission $/ \mathrm{cm}^{3}$

$R=$ the fraction of fission gases released from the fuel

$I_{2}=$ the long-lived iodine concentration $\mathrm{mg} / \mathrm{dm}^{2}$.

A factor of 2 in the denominator is applied to fuel which is predominately thoria. This assumed factor is based on the work of Clayton (Reference 19), in which iodine gas absorption was measured for thoria powders. In general, thoria powders retained about one-half the amount of absorbed iodine up to $800^{\circ} \mathrm{C}$. Since all of the rods in this report contain predominately thoria-based fuel, the factor of two is applied to all samples.

The fuel depletion (D) given in the above equation is calculated as a rod-average value. This value is less than the peak (sample) value listed in Table II of the text. A general correlation was used to translate peak depletion into rod-average depletion. Based upon the observation of early irradiated test rods

Rod-Average Depletion $=0.85 \times$ Peak Depletion for Short Rods $\left(<10^{\prime \prime}\right.$ Long $)$

and

Rod-Average Depletion $=0.75 \times$ Peak Depletion for Long Rods ( $>10^{\prime \prime}$ Long).

$V_{f}$ (volume of fuel) and $A_{c}$ (area of the clad) are dimensional parameters which are obtained from the geometry of the fuel pellet and rod.

The value of $R$ (fission gas fraction) is determined by the type of calculation which is performed. For example, $R$ was determined from three sources:

1. As the percentage of theoretical fission qas experimentally determined in the rod during post irradiation examination

2. As the maximum amount of fission gas release calculated to occur using the model described in Ketaranria 2:.4

3. As the best estimate of the fission gas release calculated to occur using the model described in Reference 23.

These values of $R$ are more simply designated as (a) measured, (b) upper-bound, and (c) best-estimate.

It is important to observe that each component of the formula for iodine concentration has some measurement uncertainty. Even the fission product iodine weight yield presented in Table I has a relatively large error band, reported to be as much as \pm 16 percent for the fissioning of uranium-233 in Reference 17. The fuel depletion (D) is only as precise as the fission power measurements which were obtained during the irradiation history of a test rod. A tolerance of \pm 6.4 percent is assumed for the burnup values of these rods when they are used for analytical purposes. It is estimated that the calculation of iodine at the pellet surface is associated with an error band of about \pm 20 percent.

Finally, the iodine value calculated from this model represents a rod averaged concentration. That is, the fission product iodine is assumed to be distributed uniformly upon the cladding inside diameter. This assumption is evidenced by the use of a rod-average depletion value in the calculation for longlived iodine concentration. 


\section{SUMMARY OF RESULTS}

\section{A. Radiochemical Analysis}

The iodine and cesium concentrations obtained from radiochemical analysis of the test rods are reported in Table II. A summary of the irradiation history of each test rod is also included as part of the listing in this table. Examination of the data shows that the amount of iodine associated with the cladding ranged from less than 0.01 to $0.8 \mathrm{mg} / \mathrm{dm}^{2}$ and the amount of cesium ranges from 0.3 to $5 \mathrm{mg} / \mathrm{dm}^{2}$. Since the fission product yield of cesium is at least ten times that of iodine, the higher level of cesium was expected.

Table IV compares the measured cladding iodine to the iodine calculated using the model presented in Section IV. The iodine concentration is calculated for three cases of fission gas release: measured, best estimate, and upper bound model. Figures 1, 2, and 3 show the measured long-lived iodine associated with the cladding compared to the iodine calculated from the measured fission gas, best estimate and bounding models, respectively. Figures 1 and 2 show that there is a relatively good linear correlation between the observed and predicted variables. The r values for these correlations are 0.73 and 0.63 , respectively, with $\mathrm{r}=0$ rejected as a null hypothesis $(\alpha<0.05)$ in both cases. These correlations imply that the iodine concentration at the cladding surface is linearly proportional to the amount of fission gas release as predicted by the model.

It should be noted however, that the upper bound calculation presented in Figure 3 does not bound all points. A radiochemical analysis of rod $79-617$ showed an iodine concentration in the cladding about 20 percent higher than the upper bound calculation. However, resampling of the retainer section of 79-617 showed iodine concentrations almost an order of magnitude less than the first measurement (see Table II). Since this second iodine determination was obtained with a larger iodine carrier yield, it is considered to be a more accurate measurement. The resampled data remains well below the upper bound calculations.

\section{B. Electron Microprobe Evaluation}

Electron microprobe examination of cladding segments from four irradiation test rods was also conducted to determine iodine and cesium distribution on the inside diameter surface of cladding. A detailed description of the analytical procedure is contained in Appendix C. A brief summary of the results is presented below. See Table C-l for power and burnup history.

\section{79-506}

Relatively high concentration of certain volatile fission products (iodine, cesium, and tellurium) were observed on the clad surface at a location corresponding to a pellet-to-pellet interface region. In addition, a high concentration of mercury was detected at the same location. The behavior, while similar to the results for the Maine Yankee Core with respect to cesium and iodine distribution, (Reference 21), was unusual because of the presence of mercury, which is not a fission product. (The mercury is assumed to occur from accidental contamination or as a tramp impurity during fuel manufacture.) No cadmium. was detected above the sample background level.

\section{2. $79-442$}

One of the two locations, corresponding to a pellet interface location on the clad surface showed only barely detectable amounts of cesium. The second interface location displayed only background levels. No iodine, cadmium, tellurium or mercury were detected above the background levels anywhere on the sample.

\section{3. $79-478$}

Neither pellet interface showed any volatile fission product (iodine, cesium, cadmium, and tellurium) above the sample background level. 


\section{79.576}

One of the two pellet-to-pellet interfaces on the cladding surface showed a relatively strong indication of cesium. No iodine, mercury, cadmium, or tellurium were detected above the sample background levels.

In all of the microprobe samples examined, there was no evidence of stress corrosion cracking. Neither stereomicroscopic nor electron microprobe examinations revealed an y evidence of cracks.

\section{DISCUSSION}

\section{A. Iodine Concentration in the $\overline{\mathbf{F}}$ uel Pellet}

Due to the low fission gas release rates of thoria-based fuel, it was anticipated that most of the iodine generated during irradiation would remain in the fuel pellet. The amount of iodine detected in the fuel using radiochemical analysis substantiates the hypothesis.

Table III contains a comparison of measured (long-lived) iodine generated in the fuel pellet to the theoretical amount generated during fissioning. Although the iodine in the pellet averaged about 80 percent of the theoretıcal (long-lived) iodine generated in the fuel, the measurement uncertainties as well as the calculational uncertainties can be quite large. The radiochemical procedure for iodine determination has a total error band of \pm 11 to 14 percent depending on the fissile component. The error in the estimate of theoretical (long-lived) iodine generated in the fuel is much larger. Summing the contributions of uncertainties due to fission yield and depletion gives a total uncertainty of \pm 17 to 22 percent $^{2}$ depending of the fissile component. Therefore, while comparison of theoretical calculations with the measurement iodine concentrations in the fuel show somewhat less iodine than anticipated, there is a potential for a large bias error in the calculation itself.

Although most of the data in Table III are within the error band, some values do appear genuinely low. For example, for rods 79-467 and 81-46 the measured pellet iodine was only 8 percent and 9 percent, respectively, of the theoretical yield. These low yields, however, do not seem to indicate high iodine release from the fuel for the following reasons:

1. Collected fission gas release for both rods was low -0.2 to 1.2 percent of the theoretical amount produced during fissioning.

2. Radiochemical cladding iodine measurements for these rods showed no unusually high concentrations

3. Both samples analyzed displayed low iodine carrier yields in the radiochemical analysis. Although there was no significant statistical correlation between low carrier yields and anomalous iodine results, it is believed that the accuracy of the dissolution technique may decrease when carrier yield drops below 10 percent.

It is also noted that the average theoretical percentage of iodine detected in uranium-235 fuel pellets was larger than that detected in uranium-233 fuel pellets (Table III). While the collective difference in the mean is about 36 percent, ( 80 percent versus 44 percent for uranium-235 and uranium-233, respectively), a T-test of this ditterence in the mean shows only about one-half of this difference ( 18 percent) to be statistically significant at a confidence level of 95 percent. No physical significance is attributed to this difference in the mean because of the relatively small sample size of the uranium233 fuel pellets.

\section{B. Iodine Concentration Associated With Zircaloy Cladding}

Table IV compares the iodine measured in cladding rinsing and dissolution with the iodine calculated by the iodine release calculational model presented in Section IV. Values of fission gas release

\footnotetext{
2 The \pm 17 exror band is associated with uranium-235 fissioning exclusively, whereas the larger exror band is aseociated with uranium-233 fissioning. The majority of the samples experience primarily uranium-235 fissioning. See TableII.
} 
were obtained for three different cases of the calculation: measured, best estimate, and upper bound. The amount of iodine contained in cladding rinse and dissolution is not differentiated in Table IV. since almost all the iodine detected was obtained by cladding dissolution. The fraction obtained by rinsing was usually below the level of detection $(<0.02 \mathrm{mg})$.

Figure 3 compares the measured long-lived iodine associated with the cladding to the iodine calculated from the upper bound calculational model. All measured iodine values are less than the upper limit value with the exception of rod 79-617. Upon resampling, the latter measurement of rod 79-617 (with a higher iodine carrier yield) decreased significantly when compared to the theoretical iodine estimated to be generated by the fuel.

When the measured iodine is compared to the iodine level calculated using the measured fission gas release, the results show a good linear correlation coefficient between the two variables, but a relatively poor fit.

This observation suggests that the linear model proposed for iodine release appears valid, although individual measurements may show poor agreement. This lack of individual agreement may be ascribed primarily to three factors:

1. Uncertainties in the calculation, particularly the long-lived iodine fission yield

2. Low iodine carrier yields during radiochemical analysis (as suggested by pellet iodine analysis of samples $81-46$ and $79-467$ in Section IV.A).

3. Inhomogeneous iodine distribution on the cladding (which may be inferred from multiple cladding iodine samples such as sample 79-617 or the microprobe examination of sample 79-506. It is not known, however, if these two specimens represent a general or anomalous case for low fission gas release rods.)

\section{Electron Microprobe Evaluation}

The primary objective of the electron microscope examination was to characterize the segregation of volatile fission products. In this respect, the observation that some volatile fission products are preferentially located at the pellet-to-pellet interface is verified in three out of four cesium samples examined. Evidence of iodine redistribution was found only in the 79-506 sample which also contained an unexpected deposit of mercury. The failure to detect significant amounts of iodine in the three remaining specimens is consistent with the observation of low iodine levels in the adjacent radiochemical samples from these rods. This observation is also consistent with the microprobe examination of lowfission-gas-release $\mathrm{UO}_{2}$ fuel rods (Reference 22) in which little segregation of volatile products is found. Because of its extremely low fission product yield or low release rate, cadmium was not detected in any specimen examined. The extreme scarcity of cadmium which has a fission yield of at least 20 times less than that of iodine, makes it an unlikely agent for stress corrosion cracking in thoriaurania fuel systems.

The presence of mercury on sample 79-506 is judged to be an anomalous event. Because mercury is not a fission product, it is assumed to have been introduced either as an accidental contaminant or as a tramp impurity fabricated into the fuel. The presence of mercury in rod 79-506 could have influenced the high degree of volatile fission product segregation observed in the microprobe sample. Mercury released from the fuel relatively early in life would be free to "getter" iodine and cesium, eventually forming the deposit of volatile fission products located at the pellet-to-pellet interface. The fact that fission product segregation was not observed in the three remaining microprobe samples further supports this conjecture.

\section{CONCLUSION}

It is concluded that there is essential agreement of the microprobe evaluation with the low-level of iodine found by radiochemical analysis. Results of both types of examinations (radiochemical and mirrnpinhe) suggested less iodine than calculated usinq the iodine release upper-bound calculational 
model. In one case, the radiochemical iodine measurement was greater than the upper bound model. Remeasurement of this rod, 79-617, showed a decrease in the iodine concentration to a level well below the upper-bound calculation. ${ }^{3}$ The upper-bound iodine calculation method presented in Section IV is therefore corroborated by the radiochemical data.

The presence of other volatile fission products on the cladding, cesium and tellurium were confirmed by electron microprobe evaluation. The cesium concentrations obtained from radiochemical data show that it is present on the cladding in greater concentrations than iodine, as might be expected due to its higher fission product yield. Similarly, the failure to detect cadmium on the cladding during microprobe examination was probably due to its extremely small fission product yield.

\section{ACKNOWLEDGMENTS}

The contributions of Messrs. J. T. Engel, R. C. Hoffman, D. A. Mertz, and J. Sherman to the examination program for iodine measurements on irradiated test rods are gratefully acknowledged. The authors are especially grateful to Mr. E. L. Valecko, Dr. O. O. Gamba and Mr. T. F. Anater for their contribution to the microprobe evaluation of specimens. The contributions of Mr. W. E. George and Dr. F. B. Barker in the radiochemical analysis of iodine and cesium are also gratefully acknowledged.

\section{REFERENCES}

1. B. Cox and J. C. Wood, "Iodine Induced Cracking of Zircaloy Fuel Cladding - A Review," in "Corrosion Problems in Energy Conversion and Generation," C. S. Tedman Jr., Ed., p. 275, The Electrochemical Society, Inc., Princeton, New Jersey, 1974.

2. S. Aas, K. D. Olshausen, and K. Videm, "Fuel Failures caused by Overpower Ramps," Nuclear Fuel Performance, paper 55, British Nuclear Society, 1973.

3. A. S. Bain, J. C. Wood, and C. E. Coleman, "Fuel Designs to Eliminate Defects on Power Increases," Nuclear Fuel Performance, paper 56, British Nuclear Enerqy Society, 1973.

4. J. C. Wood, B. A. Surette, I. M. London, and J. Baird, "Environmentally Induced Fracture of Zircaloy by Iodine and Cesium: The Effects of Strain Rate, Localized Stresses and Temperature, J. Nucl. Mater. 57, 155-179 (1975).

5. J. G. Weinberg, "Iodine Stress Corrosion Cracking of Zircaloy-4 Tubinģ," WAPD-TM-1048, February 1974.

6. C. C. Busby, R. P. Tucker, and J. E. McCauley, "Halogen Stress Corrosion Cracking of Zircaloy-4 Tubing," J. of Nucl. Mater., 55, 64-82 (1975).

7. R. P. Tucker, P. H. Kreyns, J. J. Kearns, "The Effects of Internal Surface Flaws, Iodine Concentration and Temperature on the Stress Corrosion Cracking Behavior of Zircaloy-4 Tubing," WAPDTM-1248, February 1976.

8. P. H. Kreyns, G. L. Spahr, and J. E. McCauley, "An Analysis of Iodine Stress Corrosion Crácking of Zircaloy-4 Tubing," WAPD-TM-1203, February 1976.

9. D. Cubicciotti, R. L. Jones, "EPRI -NASA Cooperative Project on Stress Corrosion Cracking of Zircaloys," NP-717, Final Report, March 1978.

10. N. W. Polan and R. P. Tucker, "The Susceptibility of Unirradiated Recrystallized Zircaloy-4 Tubing to Stress Corrosion Cracking," WAPD-TM-1313, December 19'7'7.

\footnotetext{
${ }^{3}$ Since the difference in iodine concentrations between the two measurements is larger than the measurement error, this would imply that there is some degree of iodine segregation on the cladding.
} 
11. B. Cox, "Environmentally Induced Cracking of Zirconium Alloys," Rev. Coatings Corros., 1, 367-422 (1975).

12. W. T. Grubb, M. H. Morgan, "Cadmium Embrittlement of Zircaloy-2," Proceedings of ANS Topical Meeting on Water Reactor Fuel Performance, St. Charles, Illinois, May 1977.

13. G. N. Walton, B. Bowles, and I. F. Croall, "The Condition of Fission Product Iodine in Irradiated Uranium Metal," 155-162, Geneva Conference, 1955.

14. D. Geithoff and V. Schneider, "Prevention of the Volatilization of Fission Iodine in the Dissolution of $\mathrm{UO}_{2}$ Samples," Institute of Radiochemistry, Karlsruke, April 1964 (ACE-tr-6659)

15. B. A. Rhodes, "Liquid Scintillation Counting of Radio-iodine," Analytical Chem. 37, 995-997, (1965).

16. A. W. Castleman, Jr., N. Tang, "Vaporization of Fission Products from Irradiated Uranium-II," J. Inorg. Nucl. Chem. 32, 1057-1064 (1970)

17. E. Meek and B. F. Rider, "Compilation of Fission Product Yields," Vallecitos Nuclear, NEDO$12154-1,1974$.

18. J. C. Clayton, "Some Studies on the Oxidation States of Fission-Product lodine (1-129) in Irradiated $\mathrm{UO}_{2}, "$ WAPD-TM-851, July 1969.

19. J. C. Clayton, "Fission-Product Iodine in Thoria/Urania Oxides," WAPD-TM-1148, February 1979.

20. T. R. England, W. B. Wilson, M. G. Stanmatelatos, "Fission Product Data for Thermal Reactors," (Final Report) E.PRT NP-356, December 1976.

21. N. Fuhrman, et al., "Evaluation of Fuel Performance in Maine Yankee Core/Task C," EPRI NP218 , Final Report, 1976.

22. D. Cubicciotti, et al., "The Nature of Fission Deposits Inside Light Water Fuel Rods," Proceedings of ANS Topical Meeting on Water Reactor Fuel Performance, St. Charles, Illinois, May 1977.

23. I. Goldberg, G. L. Spahr, J. F. Giovengo, L. A. Waldman, "Fission Gas Release for $\mathrm{ThO}_{2}$ Fuels," ANS Transactions, Vol. 27, No. 1, 308-310, 1977. 
TABLE I. LONG-LIVED IODINE YIELD

Iodine Isotope Yield Atom/Fission ${ }^{1}$

Iodine

Isotope

${ }^{127} \mathrm{I}$

${ }^{129}$ I

0.0080
From ${ }^{235} \mathrm{U}$

0.00136

0.00136

0.017
From ${ }^{233} \mathrm{U}$

$\begin{aligned} & =2.001 \times 10^{-24} \\ & \text { iodine } / \text { fission }\end{aligned}$

${ }^{233} \mathrm{U}=3.930 \times 10^{-24} \mathrm{gm}$ long-lived ivuline/lissiủn

\footnotetext{
${ }^{1}$ Data source: References 18 and 19
} 
TABLE II. IODINE AND CESIUM DAT A SUMMARY

\begin{tabular}{|c|c|c|c|c|c|c|c|}
\hline Rod & $\begin{array}{l}\text { Fuel R } \\
\begin{array}{l}\text { Predominant } \\
\text { Fissile } \\
\text { Component }\end{array}\end{array}$ & $\begin{array}{c}\text { od Attribute } \\
\text { Sample } \\
\text { Depletion } \\
\left(10^{20} \mathrm{f} / \mathrm{cc}\right)\end{array}$ & $\begin{array}{l}\text { Rod } \\
\text { EFPH }\end{array}$ & $\begin{array}{c}\text { Measured } \\
\text { Fission Gas } \\
\text { Release } \\
\text { (\% Theoretical) }\end{array}$ & $\begin{array}{c}\text { Pellet } \\
\text { Dissolution } \\
\text { (\% Theoretical) }\end{array}$ & $\begin{array}{c}\text { Measured Iodine } \\
\text { Total Cladding I } \\
\text { (Rinse and Dissolve) } \\
\mathrm{mg} / \mathrm{dm}^{2}\end{array}$ & $\begin{array}{c}\text { Measured Cesium } \\
\text { Total Cladding Cs } \\
\text { (Rinse and Dissolve) } \\
\text { mg/dm } 2\end{array}$ \\
\hline $79-429$ & U-235 & $\begin{array}{l}1.1 \\
0.34\end{array}$ & $\begin{array}{l}4,440 \\
4,440\end{array}$ & $\begin{array}{l}0.1 \\
0.1\end{array}$ & $\begin{array}{l}60 \\
88\end{array}$ & $\begin{array}{r}\leqslant 7 \times 10^{-5} \\
9 \times 10^{-4}\end{array}$ & \\
\hline $79-481$ & U-233 & 11.6 & 10,960 & 2.8 & $\begin{array}{l}39 \\
71\end{array}$ & $\begin{array}{l}0.33 \\
0.79\end{array}$ & 5.01 \\
\hline $79-4^{\circ} ?$ & $\mathrm{U}-233$ & $\begin{array}{l}10.3 \\
10.3 \\
10.3 \\
10.3\end{array}$ & 8.540 & 0.5 & $\begin{array}{l}14 \\
11 \\
75 \\
32\end{array}$ & $\begin{array}{l}0.041 \\
0.21\end{array}$ & 0.82 \\
\hline $79-449$ & U-233 & 10.3 & 8,540 & 0.5 & 81 & 0.013 & \\
\hline $79-506$ & $\mathrm{U}-235$ & 4.8 & 12,080 & 2.0 & & & \\
\hline 79.439 & U-233 & $\begin{array}{l}5.4 \\
5.4\end{array}$ & $\begin{array}{l}3,700 \\
3,700\end{array}$ & $\begin{array}{l}0.4 \\
0.4\end{array}$ & $\begin{array}{l}45 \\
62\end{array}$ & 0.045 & \\
\hline $79-478$ & U-235 & 11.7 & 11,020 & 2.6 & 102 & $\begin{array}{l}0.07 \\
0.038\end{array}$ & 3.15 \\
\hline $79-610$ & U-235 & 2.73 & 3,650 & 0.8 & 99 & 0.011 & \\
\hline $79-586$ & U-235 & 3.3 & 14,360 & 1.0 & & 0.035 & \\
\hline $79-572$ & U-235 & 3.9 & 14,360 & 0.1 & 84 & 0.019 & \\
\hline $81-46$ & U-233 & 8.0 & 10,300 & 0.2 & 9 & 0.071 & 0.42 \\
\hline $75-591$ & U-23E & 6.9 & 6.900 & 0.2 & 74 & 0.034 & 0.30 \\
\hline $79-467$ & U-235 & 6.01 & 16,400 & 1.2 & 8 & 0.011 & 0.47 \\
\hline $79-551$ & $\mathrm{U}-235$ & 1.75 & 3,245 & 0.9 & 101 & 0.015 & 0.21 \\
\hline
\end{tabular}


TABLE II (Cont)

\begin{tabular}{|c|c|c|c|c|c|c|c|}
\hline Rod & $\begin{array}{c}\text { Fuel } \\
\begin{array}{c}\text { Predominant } \\
\text { Fissile } \\
\text { Component }\end{array} \\
\end{array}$ & $\begin{array}{c}\text { lod Attribu:e } \\
\text { Sample } \\
\text { Depletior: } \\
\left(10^{20} \mathrm{f} / \mathrm{cc}\right) \\
\end{array}$ & $\begin{array}{c}\text { Rod } \\
\text { EFPH }\end{array}$ & $\begin{array}{c}\text { Measured } \\
\text { Fission Gas } \\
\text { Release } \\
\text { (\% Theoretical) } \\
\end{array}$ & $\begin{array}{c}\text { Pellet } \\
\text { Dissolution } \\
\text { (\% Theoretical) } \\
\end{array}$ & $\begin{array}{c}\text { Measured Ioding } \\
\text { Total Cladding } 1 \\
\text { (Rinse and Dissolve) } \\
\mathbf{n g}^{2} / \mathrm{Am}^{2} \\
\end{array}$ & $\begin{array}{c}\text { Measured Cesium } \\
\text { Total Cladding } C_{8} \\
\text { (Rinse and Dissolve) } \\
\mathrm{mg} / \mathrm{dm}^{2} \\
\end{array}$ \\
\hline $79-605$ & U-235 & 12.8 & 14,490 & & 113 & 0.36 & 2.1 . \\
\hline $79-353$ & U-235 & $\begin{array}{l}3.0 \\
3.0 \\
2.9 \\
2.9\end{array}$ & 11,490 & * & $\begin{array}{l}89 \\
75\end{array}$ & $\begin{array}{l}0.12 \\
\leqslant 8 \times 10^{-4} \\
0.08 \\
0.10\end{array}$ & $\begin{array}{l}4.01 \\
0.49 \\
0.79 \\
2.83\end{array}$ \\
\hline $79-576$ & U. 235 & 6.48 & 113,170 & 0.4 & 38 & 0.014 & 0.35 \\
\hline $79-617$ & U. 235 & 4.68 & 3,900 & 0.1 & 104 & $\begin{array}{l}0.16 \\
0.021\end{array}$ & $\begin{array}{l}0.40 \\
1.08\end{array}$ \\
\hline *79-587 & U-235 & 2.3 & 7,760 & 0.5 & 82 & $\begin{array}{l}0.011 \\
0.024\end{array}$ & $\begin{array}{l}0.96 \\
0.67\end{array}$ \\
\hline $81-76$ & U-233 & 7.09 & & 0.1 & 47 & 0.52 & 1.77 \\
\hline $79-593$ & U-235 & 6.3 & 6,340 & ** & 71 & $\leqslant 1 \times 10^{-3}$ & 0.74 \\
\hline $79-671$ & U-235 & 6.7 & 14,430 & 0.3 & 22 & 0.12 & 1.24 \\
\hline
\end{tabular}

${ }^{\star}$ Rod failed in-pile during up-p.swer transient

**Rod not drilled Sor fiss:on gas 


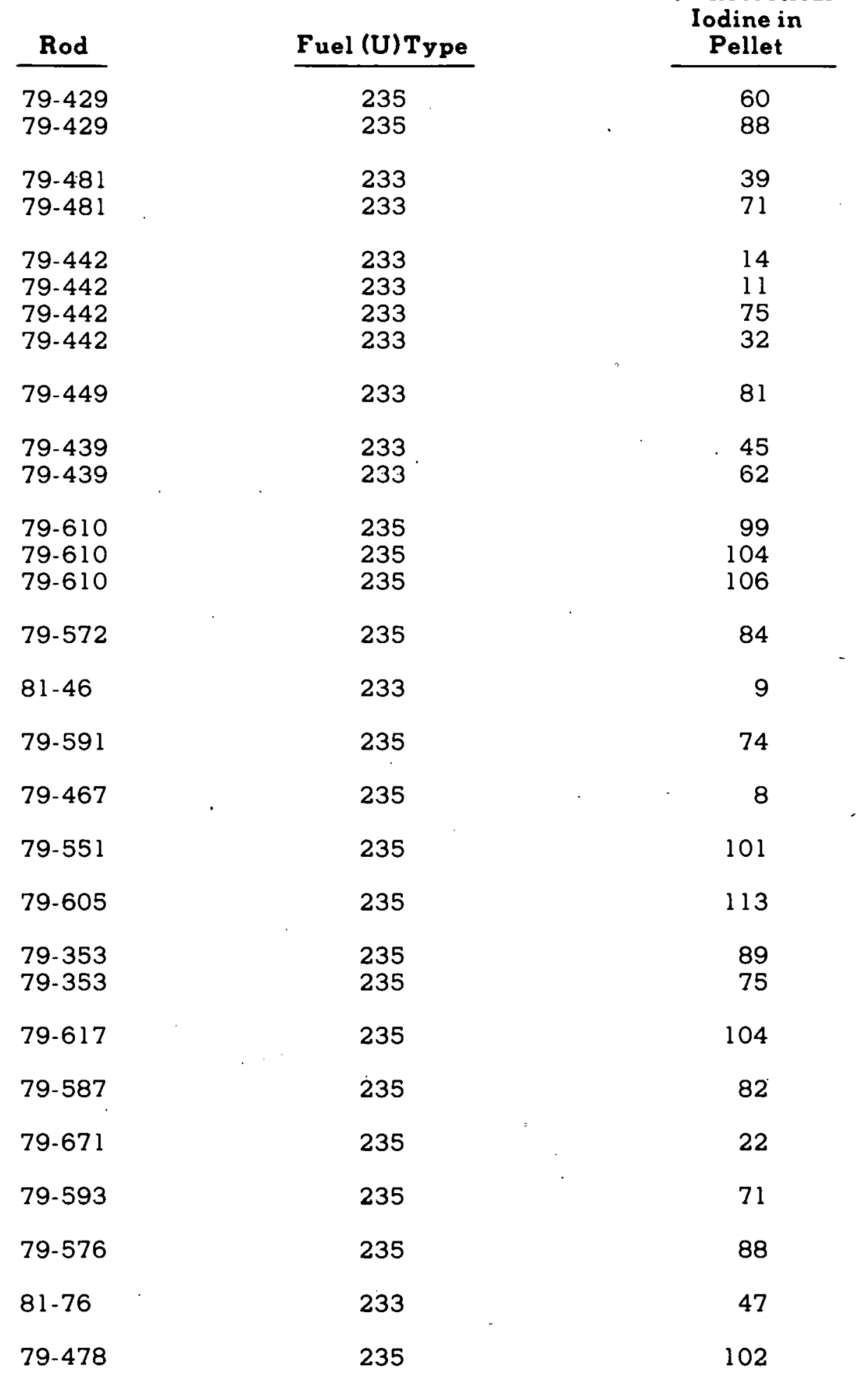


TABLE IV. MEASURED CLADDING IODINE VERSUS CALCULATED CLADDING IODINE

Rod

$79-429$

(2 samples)

$79-481$

(2 samples)

$79-442$

(2 samples)

$79-449$

$79-439$

79-610

79-478

(2 samples)

79-586

79.572

81.46

79.591

79.467

$79-551$

79.353

(4 samples)

$79-576$

79-617

(2 samples)

79.671

$79-593$
Measured Iodine

from Radiochemical

Analysis (mg/dmin

$\leqslant 7 \times 10^{-5}$

0.0009

0.329

0.79

0.041

0.21

0.013

0.045

0.011

0.038

0.070

0.035

0.019

0.071

0.034

0.011

0.015

0.08

0.10

0.12

$\leqslant 8 \times 13^{-4}$

0.014

0.021

0.10

$\leqslant 1 \times 10^{-3}$
Calculated Iodine from

\begin{tabular}{lcc}
\hline Measured Fiss Gas & LWBR Best-Es:imate & LWBR Design Gas \\
Release (mg/dm $\left./ \mathrm{dm}^{2}\right)$ & Gas Releasa $\left(\mathrm{mc} / \mathrm{dm}^{2}\right)$ & Release $(\mathrm{mg} / \mathrm{dm})$ \\
\hline
\end{tabular}

Release (mg/dm ${ }^{2}$ ) Gas Releasa $\left(\mathrm{mg} / \mathrm{dm}^{2}\right)$

0.0008

0.0 .12

0.042

0.546

0.331

0.955

0.104

0.269

0.787

0.103

0.044

0.0027

0.205

0.033

0.010

0.236

0.055

0.021

0.085

0.0475

0.0214

0.189

0.0316

0.0581

$0 . C 581$

0.006

0.027

0.629

$0 . C 20$

$0 . C 69$
0.636

0.143

0.047

0.706

0.205

0.136

0.407

0.389

0.441

0.112

0.178

0.232

0.099

0.107

0.223 


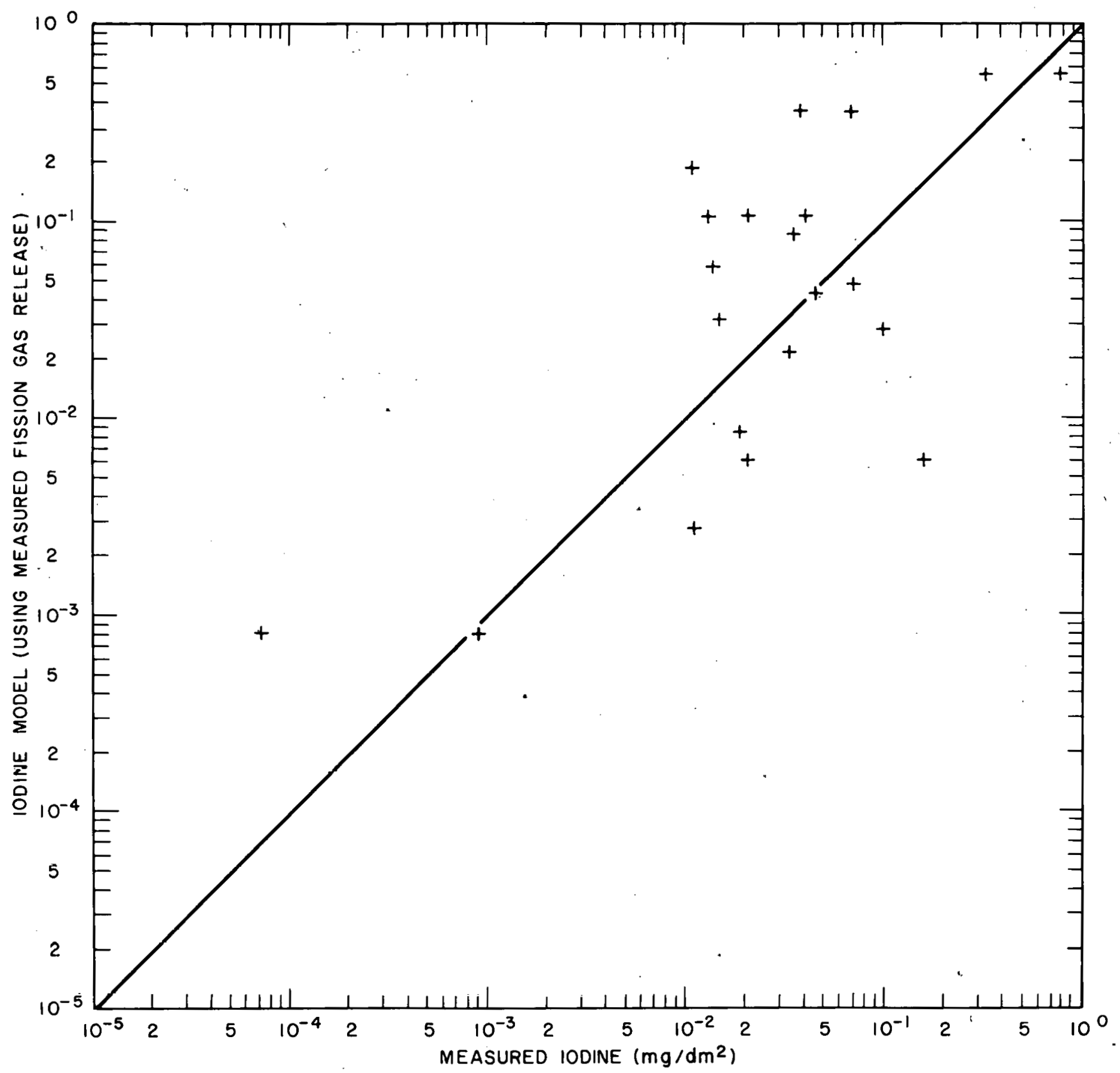

Figure 1. Comparison of Iodine Found by Cladding Rinse and Dissolution to Iodine Calculated With Model Using Measured Fission Gas Release 


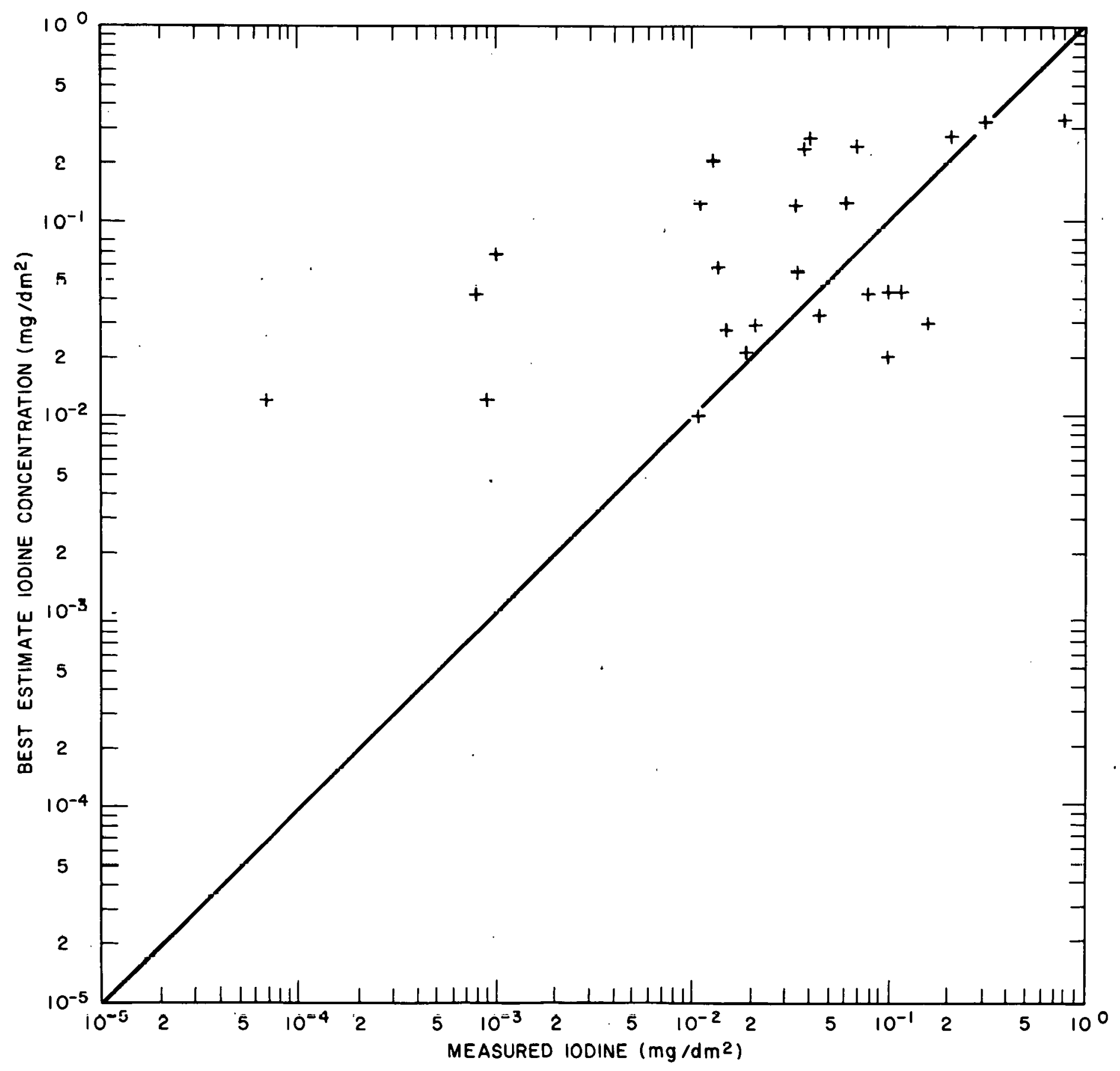

Figure 2. Comparison of Iodine Found by Clad Rinse and Dissolution to Iodine Calculated With Model Using Best Estimate Fission Gas Release 


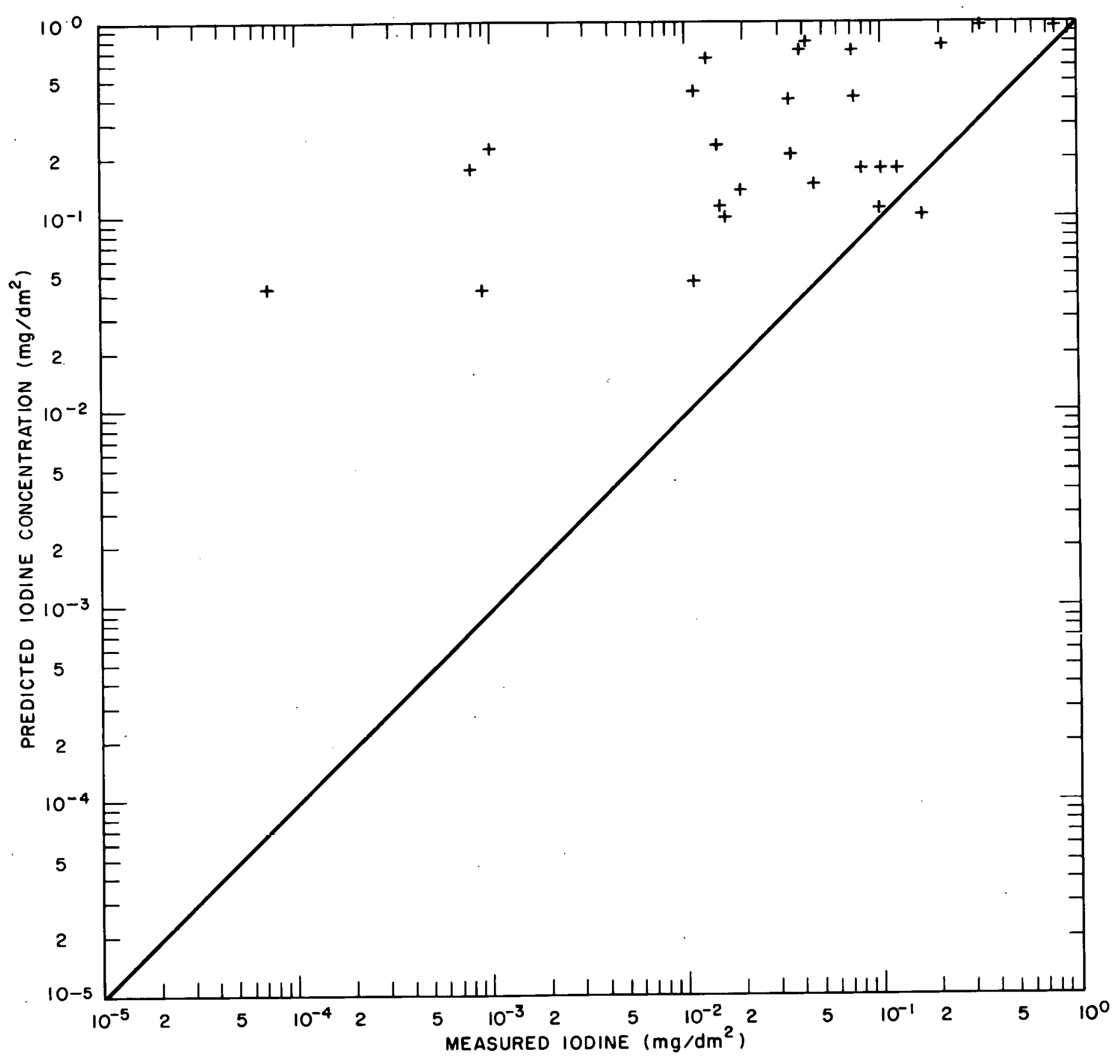

Figure 3. Comparison of Cladding Iodine Concentration: Upper Limit Basis Predictions Versus Measured Values 


\section{APPENDIX A CLAD SLITTING FOR THE PREPARATION OF IODINE/CESIUM SAMPLES}

\section{A. Rod Sectioning}

The first step toward obtaining a section of an irradiated fuel rod for iodine/cesium analysis is to drill the rod and collect all internal gases. Following this, the cladding of the rod is scribed and cut to remove a rod segment containing three or four fuel pellets. Cutting positions are specified to have the two cuts made exactly at pellet-to-pellet interfaces, thereby preventing cutter fracturing of the fuel pellet with undesirable transfer of iodine from the fuel to the clad due to sample separation rather than in-reactor operation. The rod segment is immediately sealed on both ends using plastic caps that snugly fit over the cladding; this is done to prevent air movement through the samples, which could possibly remove volatile fission products.

\section{B. Sample Slitting}

Iodine and cesium analyses are performed separately on the fuel and on the cladding. To separate the two components, the rod segment is first uncapped and then placed in the holding block illustrated in Figure $A-1$. The rod piece is securely clamped into the block; the block plus sample is then placed on the slitter, as also illustrated in Figure A-1.'

The slitter consists of four parts:

1. The trough where the holder plus-sample nests

2. The cutter sled, which contains a carbide tool steel 60 degree cutting tool which is position controlled by a micrometer

3. The rails on which the cutter sled rides

4. The hydraulic sled drive.

The sample rests with the longitudinal axis parallel to the rails of the slitter, as illustrated in Figure A-1. The cutter sled is positioned over the sample, and the cutting tool is lowered until it contacts the clad OD. The sled is then withdrawn away from the sample, the cutting tool is lowered $0.5 \mathrm{mil}$, and the sled-plus-tool is hydraulically traversed along the sample, thereby machining a $0.5 \mathrm{mil}$ deep groove along the entire length of clad. This groove machining operation is repeated, advancing the cutter $0.5 \mathrm{mils}$ into the cladding for each machining traverse, until through cladding breaks are visually observed in the bottom of the machined groove. The machining of that groove is then stopped. The clad is not slit entirely through for two reasons:

1. To hold the sample together while handling and machining of two more grooves.

2. To minimize damage to the fuel. Both Kollmorgen periscope and television optics are employed to visually monitor the advance of the groove-slit into the cladding so that excessive fracturing of the fuel (some of which always occurs) will be prevented.

Following formation of the first "through-clad" slit, the sample is rotated 120 degrees in the holding fixture and a second identical slit is made. This is followed by a third identical slit after another 120 degree rotation.

Throughout the slitting and subsequent operation, the air exposure of the samples is deliberately minimized to prevent unnecessary and undesirable loss of iodine. If the sample is not being worked on, it is immediately placed into a sealed aluminum container and remains there until all setup work for the next operation has been completed. 


\section{Post-Slit Processing}

The individual fuel pellets, each of which is generally in several chunks due to in-service cracking, are also stored in individual pre-weighed bottles. One of the three cladding sections, which is intended as a library retention clad piece, is then thoroughly stereo visually examined and photographed. The remaining two pieces, intended for iodine analysis, are given a brief visual examination to determine that they have the same internal appearance as the library sample. They are then quickly returned to their bottles. Dimensions of the pieces are taken during the visual examination for subsequent use in determining what surface area and volume of cladding is actually analyzed for iodine.

The pre-weighed-bottles-plus-samples (clad or fuel) are finally weighed to $\pm 0.0002 \mathrm{gms}$, and the weight of the samples is calculated. Two cladding pieces plus one fuel pellet then go on to the chemical operations to isolate and analyze for iodine (clad and fuel) and cesium (clad only, as cesium is determined in the fuel in separate depletion measurements), as discussed in Appendix B.

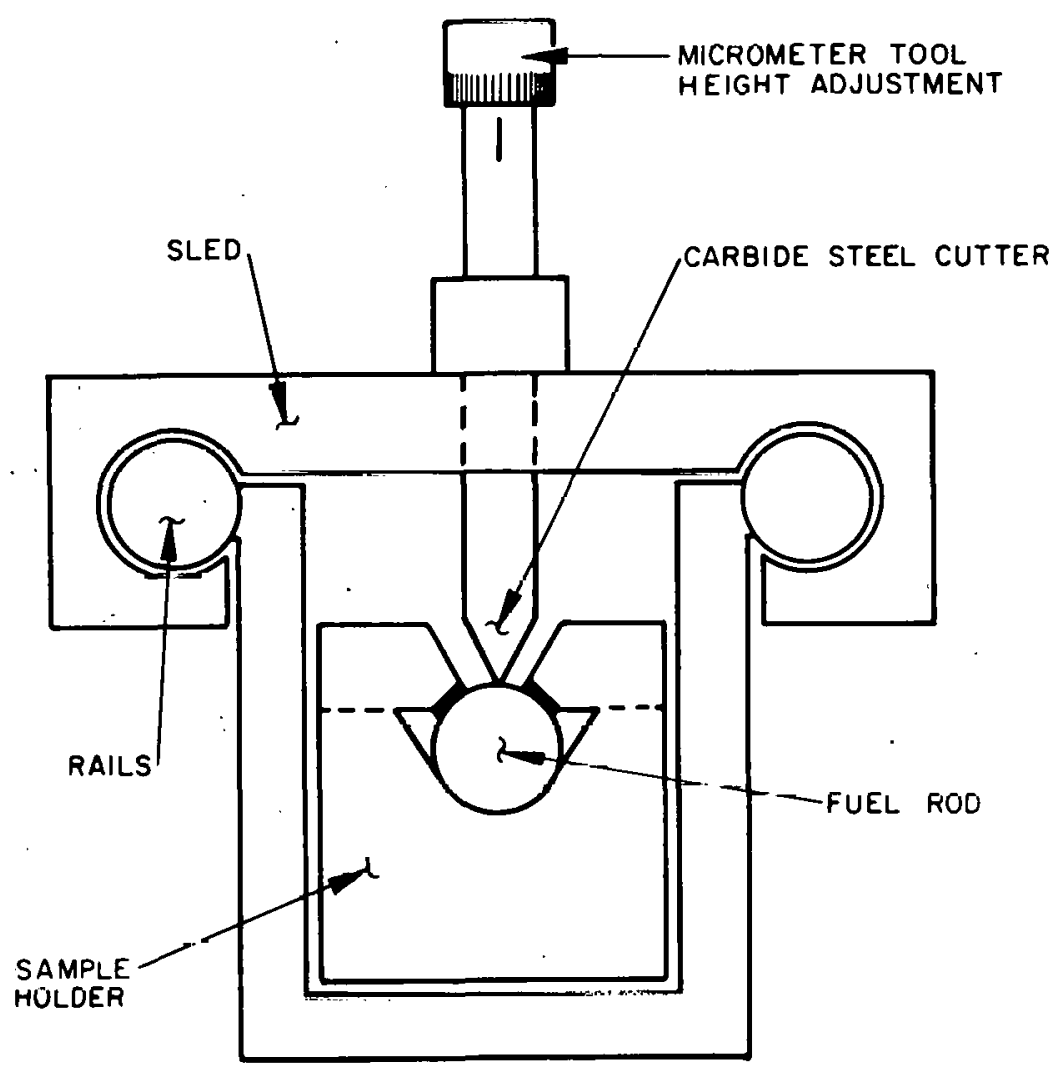

Figure A-1. Cladding Slitter 


\section{APPENDIX B RADIOCHEMICAL DETERMINATION OF IODINE AND CE- SIUM IN THE THORIA-URANIA FUEL RODS}

\section{A. Introduction}

Organic extraction is a widely used method for the direct separation of radioactive iodine and cesium from other fission products. The basic procedure for iodine detection is outlined in Reference B-1. However, since the procedure in Reference B-l was used primarily for the determination of the short-lived iodine isotopes produced in fission from micro quantities of fissile material, a new procedure was developed for determining the quantity of iodine-129( $t_{1 / 2}=1.59 \times 10^{7}$ years) produced from a macro amount of fissile material. The short-lived iodine isotopes have decayed away and the iodine- 129 found must be determined by a high sensitivity method. The analytical method chosen was to count the separated iodine fraction using a liquid scintillation detection (LSD) system where the counting efficiency for iodine-129 is approximately 80 percent. Because the specific activity of iodine-129 is low, the chemical yield ${ }^{1}$ of the iodine recovered must be in the range of 5 percent or greater.

The method presented in this Appendix for iodine- 129 determination was derived specifically for the analysis of thoria-based fuel. The method has been further refined with use to produce acceptable chemical yields. The original organic extraction performed produced satisfactory yields of 30-50 percent on the clad samples, but unsatisfactory yields of $1-10$ percent on the fuel samples. Investigation of the problem resulted in the determination that the low yields on the fuel samples were due to the long dissolution times required, the high temperatures of dissolution, and the instability of the oxidizing agent $\mathrm{NaOCl}$ under these conditions.

The procedure was, therefore, modified to improve the iodine yields. These modifications consisted of low dissolution temperatures, the use of $\mathrm{K}_{2} \mathrm{CrO}_{4}$ as the oxidant, increased amount of I carrier, and the use of $\mathrm{NaNO}_{2}$ as an additional reductant of iodine. These changes were made for irradiated fuel samples and produced iodine recoveries consistently in the range 30-60 percent.

The determination of cesium was considerably simpler than determination of iodine due in part to the decreased volatility of the sample and also to the more abundant isotope, cesium-137. Aliquots of the cesium solutions were gamma counted for cesium-137 using a gamma spectrometer and solid state GeLi detectors.

\section{B. Sample Extraction}

Iodine and cesium samples obtained either from the cladding (rinse and dissolution) or the fuel (dissolution) were extracted in the same sample solution. The extraction technique used is a function of the type of sample material to be analyzed.

A complete outline of the procedure, including reactions, is contained in the Process Flow Diagram (Chart B-1) of this Appendix.

\section{Cladding Rinse}

Free iodine and loosely-combined iodine compounds on the surface of the Ziracloy cladding are removed from the sample by a dilute hydrochloric acid rinse with ultrasonic agitation. This solution is combined with iodide carrier contained in sufficient sodium hydroxide solution to make the entire mixture alkaline. Sodium hypochlorite is added to completely convert both carrier iodine and dissolved sample iodine to the $\mathrm{IO}_{4}^{-}$oxidation state. This highest oxidation state is established to prevent a

\footnotetext{
${ }^{1}$ Because of the small quantities of materials analyzed, a known amount of carrier iodine is added to the sample at the beginning of the process. The final amount of iodine detected at the end of the procedure can thereby be compensated for processing losses. The "yield" of the extraction process is the percentage of the original carrier iodine recovered at the end of the process.
} 
volatilization of any iodine. The entire solution is then filtered to remove any particulate fuel material, and transferred from the Hot Cell Facility to the Radiochemistry Facility for further extraction and purification.

\section{Cladding Dissolution}

Combined iodine compounds remaining in the cladding are analyzed following dissolution of the rinsed Zircaloy in a nitric/hydrofluoric acid and sodium hypochlorite solution and separation by a modified iodine extraction procedure. The addition of sodium hypochlorite significantly reduces the loss by volatilization of carrier iodine and sample iodine (released from the cladding) from the hot, acidic dissolver solution.

Following sample dissolution, the solution is made alkaline and additional $\mathrm{NaOCl}$ is added to ensure that all iodine present is converted to the $\mathrm{IO}_{4}^{-}$species. The solution is re-acidified, $\mathrm{IO}_{4}^{-}$is reduced to free iodine $\left(\mathrm{I}_{2}\right)$ with $\mathrm{KNO}_{2}$, and the $\mathrm{I}_{2}$ extracted into 1,1,l-trichloroethane. The organic solution is washed with $\mathrm{H}_{2} \mathrm{O}$ plus $\mathrm{HNO}_{3}$ and $\mathrm{KNO}_{2}$, then iodine is extracted into water with $\mathrm{NaHSO}_{3}$. The aqueous iodine solution is transferred from the hot cell to the radiochemistry laboratory for further purification and analysis.

\section{Fuel Pellet Dissolution}

The total amount of tission product iodine present in the irradiated ceramic-oxide fuel sample is determined via sample dissolution in a nitric/hydrofluoric acid-potassium chromate solution followed by iodine extraction.

The majority of iodine present in the ceramic fuel pellet and released during dissolution, plus that added as iodide carrier, is held in a non-volatile form in the acidic dissolver solution by the potassium chromate. The iodine is most probably present in all its oxidation states, but predominantly in the $\mathrm{IO}_{4}^{-}$ form. The $\mathrm{IO}_{4}^{-}$plus other oxidation states are converted to free iodine, $\mathrm{I}_{2}$, by the addition of $10 \mathrm{M}$ potassium nitrite, then extracted into 1,1,1-trichloroethane after a somewhat lengthy reaction period. The iodine is converted to iodide, $\mathrm{I}^{-}$, by reaction with $\mathrm{NaHSO}_{3}$, and extracted into aqueous solution. It is then transferred from the Hot Cell Facility to the Radiochemistry Laboratory for further purification and analysis.

\section{Sample Purification (Iodine)}

\section{Iodine Obtained from Sample Rinse}

The iodine ultrasonically rinsed from the surface of Zircaloy cladding is transferred from the remote Hot Cell in approximately $150-350 \mathrm{ml}$ of $\mathrm{NaOH}$ solution. All sample iodine and carrier iodine will be of the $\mathrm{IO}_{4}^{-}$species, as oxidized by $\mathrm{NaOCl}$. This solution also contains some dissolved fission products, predominantly cesium-137 and possibly a small amount of dissolved zirconium compounds and fuel material. The sample solution is then acidified with $\mathrm{HNO}_{3}$, the iodine is reduced to $\mathrm{I}_{2}$ with $\mathrm{NH}_{2} \mathrm{OH}$ - $\mathrm{HCl}$, and the $\mathrm{I}_{2}$ is extracted into $1,1,1$-trichloroethane.

The organic solution is washed, then the iodine is extracted into water after reduction to $\mathrm{I}^{-}$with $\mathrm{NaHSO}_{3}$. The aqueous solution is acidified, the iodine is converted to $\mathrm{I}_{2}$ with $\mathrm{KNO}_{2}$, and the $\mathrm{I}_{2}$ is reextracted into 1,1,1-trichloroethane. The organic is again washed and the $\mathrm{I}_{2}$ reduced to $\mathrm{I}^{-}$with $\mathrm{NaHSO}_{3}$ and extracted into a small quantity of water. This cycle of oxidation, extraction, reduction, and back-extraction is continued until the sample is free of all but traces of cesium and cerium activities. An aliquot of the aqueous phase is then taken for liquid scintillation spectrometry; the remainder is used for determination of the total iodine chemical yield by precipitation of AgI.

\section{Iodine Obtained from Sample Dissolution}

The second type of solution transferred from the Hot Cell is approximately $25 \mathrm{ml}$ of aqueousbisulfite solution containing sample and carrier iodine as the $\mathrm{I}^{-}$species. This iodine is obtained from a dissolved Zircaloy cladding sample, or from either the free iodine extracted from a finely crushed fuel 
pellet or the total iodine from a dissolved "whole" fuel pellet. This aqueous-bisulfite solution may have undergone some air oxidation prior to transfer from the contained facility. It is therefore made basic, if necessary, with $\mathrm{NaOH}$ and all iodine species present oxidized to $1 \mathrm{O}_{4}^{-}$with $\mathrm{NaOCl}$. The remainder of the procedure is identical to that described above for rinse samples.

\section{Final Determination}

Following the above separation procedures, cesium-137 contamination of the final iodinecontaining solution may still be significant. Rather than further purification involving repeated cleanup extractions or distillations of the iodine (consequently decreasing the chemical yield), the iodine129, cesium-137, and cerium-144 are "separated" via liquid scintillation spectroscopy. Contamination by other fission products is assumed to be negligible but is also taken into account via the liquid scintillation spectroscopy procedure.

\section{Liquid Scintillation (Iodine)}

The sample aliquots prepared in Section $\mathrm{C}$ were counted on a Packard Tri-Carb liquid scintillation spectrometer, model 3375, to determine the activity of iodine-129 in the presence of any cesium-137 or other possible fission product contamination.

With respect to the counting of the separated iodine using the liquid scintillation counter, a counting time of 200 minutes per sample or a count rate of $1 \times 10^{5}$ total counts per sample was used. With most samples, the 200 minutes per sample was required of the clad and clad rinse samples, while the large count rate of the fuel samples needs a counting time of ten minutes. Use of these two parameters gives a counting error in the samples of 1 percent or less.

A more detailed error analysis of the iodine determination shows three types of errors are possible. They can be classified as:

a. Random errors associated with sample preparation and counting

b. Bias errors due to the uncertainties with respect to the half-life of iodine- 129

c. Errors due to the fission yields from uranium-233 and uranium-235.

An example of $a$ and $b$ is found in the following model used to calculate the micrograms of iodine129 in a sample:

$$
\begin{aligned}
{ }^{129} \text { I half-life } & =1.57 \times 10^{7} \text { years }=8.36 \times 10^{12} \text { minutes } \\
{ }^{129} \mathrm{I} \text { decay constant } \lambda & =\ln 2 / 8.36 \times 10^{12} \mathrm{~min}=8.29 \times 10^{-14} \mathrm{~min}^{-1} \\
\mu g^{129} \mathrm{I} & =\left(\text { Measured }{ }^{129} \mathrm{I} \mathrm{DPM}\right)^{(2)} \times\left(\frac{\mathrm{L}}{\lambda}\right) \times\left(\frac{129 \mu \mathrm{g} / \mu \mathrm{mole}}{6.022 \times 10^{17} / \mu \text { mole }}\right) \\
\mu \mathrm{g}^{129} \mathrm{I} & \left.=\left(2.584 \times 10^{-3}\right)^{129} \mathrm{I} \mathrm{DPM}\right)(\mathrm{L}) \\
\mathrm{L} & =\text { chemical yield correction } .
\end{aligned}
$$

${ }^{2} \mathrm{DPM}=$ disintegrations por minute 
Calculation of the total iodine in a sample is obtained by summing the fission yields of iodine- 129 and iodine-127, and then dividing by the fission yield of the iodine-129. Once this factor has been obtained, the iodine-129 measured is multiplied by this factor to obtain the total iodine produced. Errors due to fission product yield are used in this calculation. Thus for the fuel being either uranium235, uranium-233, or $\mathrm{Th}+$ uranium-233 the following error bands are summarized.

uranium-235

$$
\begin{gathered}
{ }^{129} \text { I error }=4.1 \%(a)+4.7 \%(b)=8.8 \% \\
\text { Total-I error }=8.8 \%(a+b)+2.3 \%(c)=11.1 \%
\end{gathered}
$$

uranium-233, Th, Th + uranium-233

$$
\begin{gathered}
{ }^{129} \text { I error }=4 ! 1 \%(a)+4.7 \%(b)=8.8 \% \\
\text { Total-I error }=8.8 \%(a+b)+5.6 \%(c)=14.4 \%
\end{gathered}
$$

\section{Gamma Counting (Cesium)}

The dissolved cladding solutions and the cladding rinse solutions are made up to a known volume in a volumetric flask; a fraction is then taken from each for cesium analyses. 'l'he remainder of each solution is kept for the fission product iodine analyses. Aliquots of individual cesium samples, after additional dilution if necessary, are transferred to individual counting vials. These vials are counted on the GeLi detector to obtain the cesium-134 and cesium-137 content. These microliter aliquots are prepared and counted in duplicate.

The samples are gamma counted using a multichannel analyzer connected to a GeLi detector. The $662 \mathrm{Kev}$ photopeak of cesium-137 and the $605 \mathrm{Kev}, 795 \mathrm{Kev}$ photopeaks of cesium-134 are used to determine the quantities of these nuclides present in the aliquots. These photopeak areas are integrated and compared to the photopeak areas of samples of known cesium-134 and cesium-137 content (standards) counted in the same geometry to obtain the cesium-134 and cesium-137 content of the sainples.

National Bureau of Standards (NBS) cesium-137 is used as the standard reference material for cesium-137, while commercially available cesium-134 is used as the other standard reference material since it is not available from NBS. The uncertainties specified consist of the sum of the random uncertainties at the 95 percent confidence level and maximum expected bias errors. The uncertainties for cesium-134 and cesium-137 determinations are \pm 8 percent and \pm 4 percent respectively.

\section{REFERENCES}

B-1. L. E. Glendenin and R. P. Metcalf, "Improved Determination of Iodine Activity in Fission," Radiochemical Studies: The Fission Products, B13, 1951. 


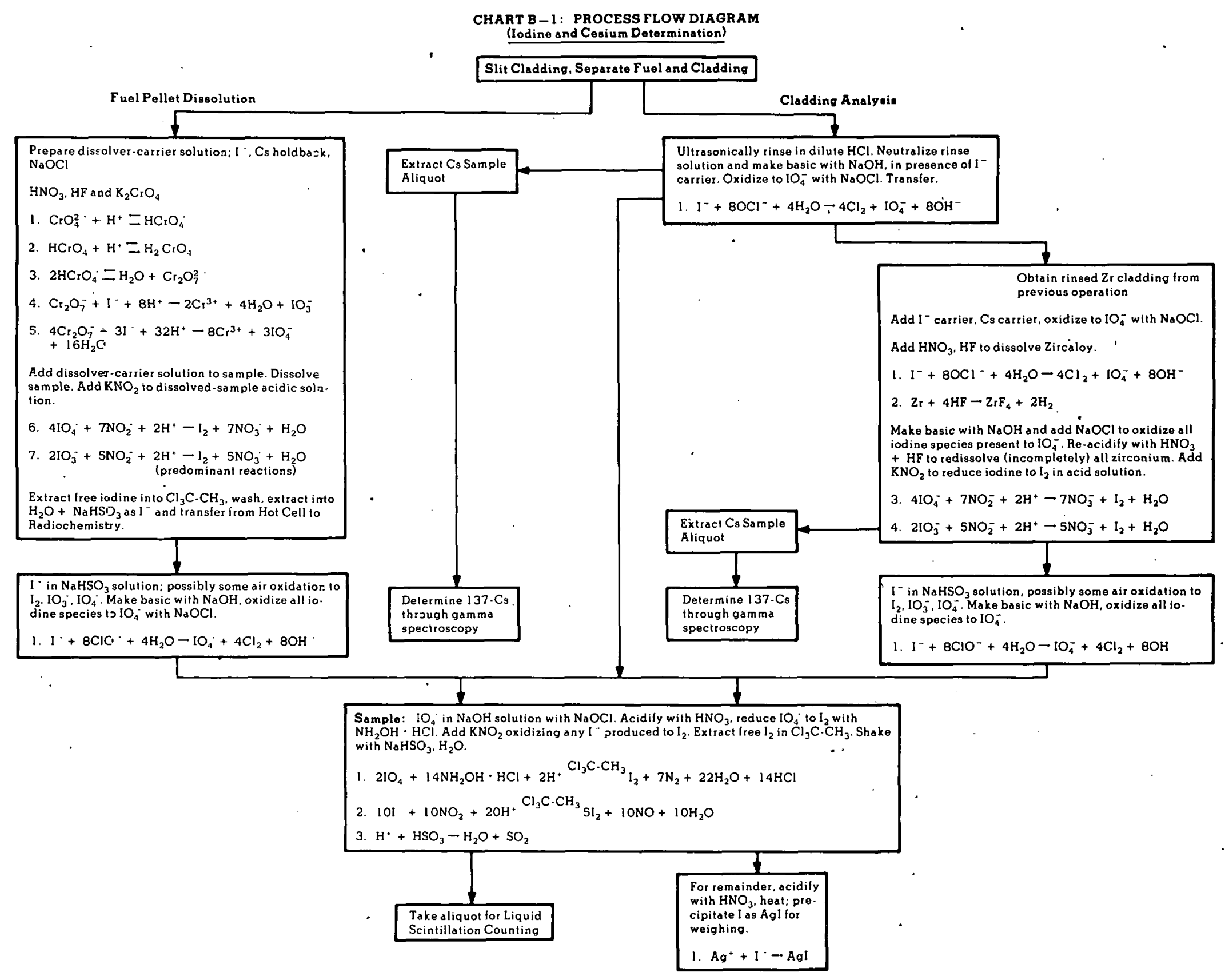




\section{APPENDIX C. ELECTRON MICROPROBE ANALYSIS OF IRRADIATED ZIRCALOY CLADDING SPECIMENS}

\section{A. Introduction}

For the identification of chemical species on the cladding of fuel elements, electron microprobe analysis offers significant advantages over radiochemical techniques. Most importantly, it can detect highly localized concentrations of materials and characterize the distribution of its chemical constituents over the region of interest. For this reason, electron microscopy (scanning and microprobe) has been employed by several investigators to study stress corrosion behavior in Zircaloy tubing. Recently, post-irradiation Ziracloy cladding examinations have been conducted at SRI and Argonne National Laboratory. Reference C-l reports fission product redistribution on the internal diameter of irradiated cladding. In this case, Cs, I, and Te compounds were found in "sharp stripes" opposite fuel cracks. Pellet-to-pellet interfaces were characterized by U, Cs deposits which in some cases appeared "bonded" to the cladding.

Other microprobe studies have confirmed fission product redistribution on the cladding, notably cesium and iodine (Reference C-2). In this case, iodine and cesium were found preferentially distributed at pellet-to-pellet interface regions of the cladding. The major difference between the microprobe examination of LWBR irradiation test cladding and the preceding post-irradiation examinations is the fuel in the rods. The fuel rods examined in Reference C-l were obtained from Maine Yankee Core 1 , and were characterized by high fission gas release (greater than 13 percent), relative low density (less than 94 percent theoretical) $\mathrm{UO}_{2}$ fuel. In contrast, LWBR rods contain a high density (greater than 97 percent theoretical), low fission gas release (less than 5 percent), $\mathrm{UO}_{2}-\mathrm{ThO}_{2}$ fuel with uranium-233 and uranium-235 fissile components.

\section{B. Sample Preparation}

\section{Sample Selection}

A circumferential retainer segment of the slit cladding radiochemistry sample was examined using an electron microprobe. Four samples were examined, one each from the highest power region of an LWBR irradiation test rod. The irradiation histories of all four samples are presented, together with the radiochemistry results for adjacent cladding segments, in Table C-l. Because of their relatively high depletions and long exposures, all four cladding samples were considered likely candidates for revealing significant fission product levels.

The basis of sample selection was to choose rods with relatively long EFPH and high total depletion to maximize the amount of fission products on the cladding ID. Further consideration was also given to sample availability and remnant pellet contamination. In some rods, the cladding cannot be separated cleanly from the fuel and adherent pieces of fuel remain. Besides providing an increased radiological hazard, this adherent fuel would obscure large areas of the cladding ID surface with an impenetrable layer of fuel. Therefore, cladding with large amounts of sticking fuel were not considered for microprobe evaluation.

\section{Visual Examination}

All slit cladding segments were visually examined using a stereomicroscope prior to sectioning for radiochemistry samples. The remaining segments selected for microprobe analysis were also visually re-examined for two reasons. The first was to locate the areas of the pellet-to-pellet interfaces, considered particularly important due to the volatile fission product reported in Reference C-1 and C-2. Secondly, since the goal of investigation was to examine the surface in-situ, no excessive adherent fuel could be tolerated. Once the cladding was separated from the fuel, no physical contact was permitted with the surface of interest. Therefore, samples with large areas of clinging fuel were not selected for analysis. The principle features of interest revealed by these visual examinations are detailed below. 


\section{a. 79.442}

This sample showed a uniform, dark oxide coating with one of the two locations corresponding to pellet-to-pellet interfaces barely visible under magnification (20X). The second interface location was not seen. Two very fine light green circumferential marks were also observed in an area between the two pellet interfaces. A sketch of the rod 79-442 cladding sample is presented in Figure C-1.

\section{b. 79.478}

This sample contained two locations corresponding to pellet-to-pellet interfaces, both of which appeared slightly lighter in coloration than the surrounding surface. A series of dark, very fine, longitudinal marks were noted between the interfaces. When viewed stereographically these marks appeared to be cracks in the oxide film. Figure C-2 shows the $79-478$ cladding sample layout for sectioning.

\section{c. 79.576}

This sample contained one location corresponding to a pellet-to-pellet interface. This location appeared darker than the surrounding area of the cladding. The same local coloration (light grecn bands) appeared further away from the interface. In this case, the bands were not oriented at right angles to the rod axis but appeared as a spiral. In addition to this, some Zircaloy chips were noted on the microprobe sample after final sectioning. (See Figure C-3.)

\section{d. 79-506}

The cladding section showed a uniform dark oxide film interrupted only by color changes at pelletto-pellet interfaces. The interfaces were distinct, with a shiny metallic orange appearance. The microprobe sample was sectioned to include one interface,approximately 0.1 inch from the sample end (see Figure C-4). Due to the restriction upon microprobe sample size, only one interface could be included on the specimen. (The shielded electron microprobe accepts a standard mount one inch in diameter, thus limiting the specimen size to a length of about 0.8 inch).

\section{Specimen Sectioning}

Final sectioning of the microprobe samples was performed within hut cell containment with a jeweler's saw. Special annular fixtures were used to hold the cladding during sectloning to eliminate contact between the surface to be probed and the brass fixture. Visual examination after sectioning showed no cross-contamination had occurred.

Some cutting chips were observed on sample 79-576; however, it was concluded that these were caused by a slight tilting of the machining jig during the final sectioning cut, thereby permitting chips produced during sectioning to fall upon the specimen surface.

Due to the restriction upon microprobe sample size, samples were sectioned to include the most definitive location corresponding to a pellet interface plus a second interface location it space permitted. For cladding samples $79-478$ and 79-442, two such pellet interface locations were included on the microprobe specimen. For $79-57 \bar{b}$, the main interface region is on the extreme end of the speci= men, while the opposite end approaches the adjacent pellet interface region but does not show the line of demarcation. Due to the length of the pellets in Rod 79-506, only one interface region could be included.

Finally, the samples were affixed to a microprobe sample holder using conductive epoxy cement, carhon coated to fix loose contamination, and transferred to the shielded electron microprobe for viewing. 


\section{Experimental Observations}

The purpose of the examination was to establish the distribution of $\mathrm{I}, \mathrm{Cs}, \mathrm{Cd}, \mathrm{Te}$, and $\mathrm{U}$ in the longitudinal direction of the rods, in an attempt to determine their degree of segregation on the ID surface. The location of the fuel pellet interfaces, where the accumulation of volatile fission products was suspected, was examined with particular interest. Considering the limitations imposed by the curvature of the analytical surfaces, the microprobe continuous $\mathrm{X}$-ray intensity profiling technique was employed. This technique performs elemental scannings along the generatrix of the inner cylindrical surface of each tube section.

\section{Sample 1: Rod 79-506}

The concentration-analog signal generated by the elements of interest while the specimen was translated under the stationary electron beam, were recorded on strip charts at the profiling rate of $60 \mu \mathrm{m}$ per minute. X-ray excitation was induced with a defocused beam (diameter estimated at 20 $30 \mu \mathrm{m}$ ), to minimize the beam energy dissipation effect on the volatile fission products under investigation. Two elements were simultaneously recorded in each scan.

No topographic characteristics indicative of the interface region could be observed with the optical system of the microprobe; the C-coated specimen exhibited a uniform black surface.

The end of the sample near the pellet-to-pellet interface has been designated End $A$. The interface of interest is located less than $3 \mathrm{~mm}$ from the edge of this section (see Figure C-1). The opposite end, End $B$, had no interface in its vicinity. By starting the profiles at a distance of $3.5 \mathrm{~mm}$ from either end, and running the scans toward the corresponding edge of the sample, both interface and interface-free data could be obtained. On this basis, the following strip chart recordings were generated:

$$
\begin{aligned}
& \text { Chart C-1: End A }- \text { I and Cs Profiles } \\
& \text { Chart C-2: End A }- \text { U and Te Profiles } \\
& \text { Chart C-3: End A }- \text { Cd and Th Profiles } \\
& \text { Chart C-4: End B }- \text { I and Cs Profiles } \\
& \text { Chart C-5: End B - U and Te Profiles } \\
& \text { Chart C-6: End B }- \text { Cd and Th Profiles }
\end{aligned}
$$

The three 2-element, $3,500 \mathrm{~mm}$ profiles obtained for each end were run over the same path on the surface. At the end of each concentration profile, the charts include a wavelength scan over the spectral region of the corresponding element. These wavelength scans indicate the background, or $U$ percent level signal of the profiled element, and permit an estimation of the concentration variations along the scan. A summary of the results is presented below.

\section{a. I and Cs Profiles}

The scans over the End A show I to be almost completely accumulated at the pellet interface band (see Chart 1); beyond this region, the I intensity is barely detectable. A minimum detectable signal was also the response recorded for I along the entire scan of End B. Cesium is also concentrated mainly at the interface band, but shows strong signals for an additional 700-800 microns after I levels off as a trace. After this second region, the Cs signal remains constant at a low level for the remainder of the End $A$ scan, and for the entire End B scan.

\section{b. Te and U Profiles}

Tellurium shows a distribution pattern similar to that of Cs. It is highly accumulated at the interface, and continues to display significant peaks in the adjacent band, where Cs also yielded high signals. Beyond this region, the Te indication is minimal for the rest of the End A scan and for the entire End B 
scan. Uranium is present at relatively uniform levels along the entire profiles over End $A$ and End $B$. The exception here is at the interface band, where the $U$ distribution shows valleys of minimum detectable signals.

\section{c. Cd and Th Profiles}

At the spectral location of the analytical Cd L $\alpha$ X-ray line, a strong interference from the Th $\mathrm{M} \beta \mathrm{X}$ ray line was observed for the sample under investigation. Under these circumstances, fluctuations in the signal recorded at the $\mathrm{Cd}$ L $\alpha$ wavelength setting could be attributed to level changes of either Cd or Th, or both; no unambiquous data can be obtained from this signal alone. To retrieve any true Cd net signal fluctuation during the profiles, both elements were scanned simultaneously-Cd at the Cd L $\alpha$ shoulder of the Th $\mathrm{M} \beta$ peak, and Th at the peak of the uninterferred $M \alpha$ line. As shown by Chart 3 and Chart 6, the amplitude of the signal recorded at the Cd L $\alpha$ setting coincides with the intensity of the Th $M \beta$ contribution; the fluctuations of this signal along the End $A$ and End $B$ profiles coincide with the fluctuations recorded for the Th $\mathrm{M} \alpha$ signal. These $\mathrm{Cd}-\mathrm{Th}$ profiles indicate no net signal assignable to $\mathrm{Cd}$ along the scans, and Cd is considered not detected in either section end. ( $A$ diverging Cd signal at one section edge is an $\mathrm{X}$-ray optics effect resulting from edge topography and should be disregarded as a concentrational signal.)

\section{d. Qualitative Ánalysis (79-506)}

To gain some understanding of the reasons for this preferential fission product distribution, a complete qualitative analysis for all elements above atomic number 12 (Mg) was performed for each region. This analysis was done using $\mathrm{X}$-ray wavelength dispersive spectrometry. The findings are summarized in Table C-2.

Although the same elements were detected for Regions 1 and 2, the relative levels shown by some of them varied greatly between the regions. Molybdenum, a fission product which forms volatile cesium molybdate $\left(\mathrm{Cs}_{2} \mathrm{MoO}_{4}\right)$, was found in the interface region and an adjacent area, but not in any other portion of the sample.

The presence of $\mathrm{Hg}$, and the magnitude of the $\mathrm{X}$-ray intensities at which it was recorded, constituted a most unexpected finding of the qualitative analysis. Because of the significance of the presence of this contaminant in SCC test specimens, additional effort was applied to assess its distribution with respect to the pellet interface band and adjacent regions. This was accomplished by profiling simultaneously for $\mathrm{Hg}$ and I, and subsequently for $\mathrm{Hg}$ and $\dot{C}$, along paths over End $\AA$. The recorded scans are attached as Charts C-7 and C-8. The Hg profile shows this element to be accumulated at the pellet interface band, yielding minimum signals at the adjacent region. Iodine is retained within the same band, and the coincidental $\mathrm{Hg} / \mathrm{l}$ concentration pattern suggests a combination between these elements. The $\mathrm{Cs} / \mathrm{Hg}$ profiles confirm previous findings: the $\mathrm{Hg}$ distribution is constrained to the interface band, while the $\mathrm{Cs}$ has been able to reach surface regions beyond this band.

\section{Samples 2, 3, 4: 79.442, 79.478, 79.576}

It was proposed that data on fission product distribution be obtained by the X-ray elemental profile scan technique, which had been employed with success on the first sample. However, the three remaining samples were found not to exhibit distributions amenable to this technique. Whereas the accumulations of fission products in the first sample were substantial, only minimal signals were obtained on the remainder. Regions of discernible preferential distribution, indicative of pellet interfaces, were generally not observed along longitudinal scanning paths for these three sections. Consequently, the analytical strategy was changed to qualitative analyses at selected spots. It should be noted that in most cases the Zircaloy major constituents were also detected, but are not listed here. The detected fission products yielded extremely weak signals, indicating only minimal concentrations. Elements specifically sought but not detected were $\mathrm{Hg}, \mathrm{Cd}$ and $\mathrm{I}$. 


\section{a. Sample 79-442 (GRIP-II)}

One of the two locations corresponding to pellet interfaces showed detectable amounts of cesium, the second interface location displayed only background levels. There was a very small cesium concentration in the vicinity of a green scratch located between pellet interfaces. The results of the qualitative analysis of selected spots is presented in Table C- 3 .

\section{b. Sample 79.478}

Although some cesium was detected on the sample, no cesium significantly above the background level was associated with either of the two pellet interface locations.

A listing of the elements identified in the spot analysis is presented in Table C-3.

\section{c. Sample 79.576}

One pellet-to-pellet interface location showed no distinguishing fission product, while the second interface location exhibited the strongest indication of cesium detected since sample 79-506. Although this interface location lacked the characteristic line of pellet demarcation (visable circumferential marking), it appeared to be a portion of an actual interface due to its predicted location and the local depletion of uranium and thorium on the cladding surface region characteristic of a tapered pellet location. (Rod 79-506 also showed a decrease in uranium and thorium in the area of the pellet interface.)

A list of the areas scanned on this specimen is presented in Table C-3. The approximate locations of these analytical areas are shown in Figure C.5.

\section{Discussion and Conclusions}

The results of the electron microprobe analyses of four LWBR irradiation test fuel rod cladding specimens are similar to the findings from commercial $\mathrm{UO}_{2}$ fuel core rods for the Maine Yankee and H. B. Robinson Core (References $\mathrm{C}-\mathrm{l}$ and $\mathrm{C}-3$ ). The observation that volatile fission products are preferentially located at the pellet-to-pellet interface is verified in 3 of the 4 cesium samples examined. Evidence of an iodine distribution was found only in the 79-506 sample, which also contained unexpected levels of mercury. The failure to detect significant amounts of iodine in the three remaining specimens is consistent with the measured radiochemical iodine samples taken from adjacent cladding. The radiochemical results indicate a level of iodine which is less than the estimated limit of detectibility of the microprobe. It is also noted that microprobe examinations of low-fission gas-release $\mathrm{UO}_{2}$ fuel rods have sometimes shown little or no detectable iodine (Reference C-3). Thus the general assessment of volatile fission product distribution on LWBR fuel rod cladding indicates that there is some preferential cesium concentrations at pellet-to-pellet interface regions, but that there is little or no detectable iodine segregation. (It should be noted, however, that radiochemical data indicate cesium concentrations exceed iodine concentrations in all cases, so that detection of cesium at the interfaces may well be a consequence of its relative abundance.)

The relatively large concentration of mercury revealed by electron microprobe examination of sample 79-506 is believed to be contributory to the high local iodine presence of the sample. The suspected mechanism for this behavior is that the mercury, present as a result of foreign contamination in the fabricated pellet, is released from cracked fuel early in life and deposited on the cladding with possible segregation to relatively cooler cladding regions at the pellet tapers. This mercury-rich deposit would then be free to "getter" iodine being released from the fuel during irradiation. Although the source of the mercury is not known (accidental contamination or tramp impurity) it appears to be an unusual event because it is present only in rod 79-506. Rods 79-442,79-478, and 79-576 showed no detectable mercury when microprobed.

In addition to iodine and cesium, the distribution of cadmium was also investigated. No cadmium was detected on any portion of the four microprobe samples despite the use of uranium-235 based fuel. 
Thus, it is judged that cadmium is not a likely agent for stress corrosion failure in LWBR core rods, stemming no doubt, from the fact that its fission product yield is a factor of 30 less than the fission product yield of iodine for uranium-235. ${ }^{(1)}$

No evidence of cracking was observed in any of the four cladding specimens. (The "cracking" which was observed on 79-478 (Section B.2) was confined to the oxide layer.) This is true not only for the optical examinations before and after carbon coating, but also for the areas examined during microprobe analysis. The optical resolution of the carbon-coated sample in the hot microprobe was particularly poor and only the largest of cracks could have been identified. Therefore, the characterization of incipient cracking would occur only if it were struck "accidentally" by the electron beam. During the analysis, only a small area of the sample (about $0.007 \mathrm{square}$ inch) was actually examined by the beam.

In conclusion, although cesium appears to be preferentially associated with the pellet interface region of the cladding, iodine does not. ${ }^{2}$ The presence of iodine at the pellet interface in rod 79-506 is considered an anomalous case. The presence of mercury in rod 79-506 is believed to have enhanced the iodine concentration by acting as a chemical "getter."

\section{REFERENCES}

C-1. N. Fuhrman, et al, "Evaluation of Fuel Performance in Maine Yankee Core l Task C," EPRI NP218 , Final Report, November 1976.

C-2. Davies, et al, "Irradiation Tests to Characterize the PCI Failure Mechanism," Haldn Program Group Meeting on Water Reactor Fuel Performance, Sanderstohn, Norway, March 1977.

C-3. D. Cubicciotti, et al, "The Nature of Fission Deposits Inside Light Water Fuel Rods," Proceedings of ANS Topical Meeting on Water Reactor Fuel Performance, St. Charles, Illinois, May 1977.

\footnotetext{
${ }^{1}$ The fission product yield of long-lived cadmium is 20 times less than that of iodine for uxanium-235. Use of uranium-233 fissions raises this ratio to a factor of 30 .

${ }^{2}$ Iodine concentration less than the minimum detectable amount cannot be resolved on the electron microprobe. Therefore, iodine does not appear segregated below the minimum detection level.
} 


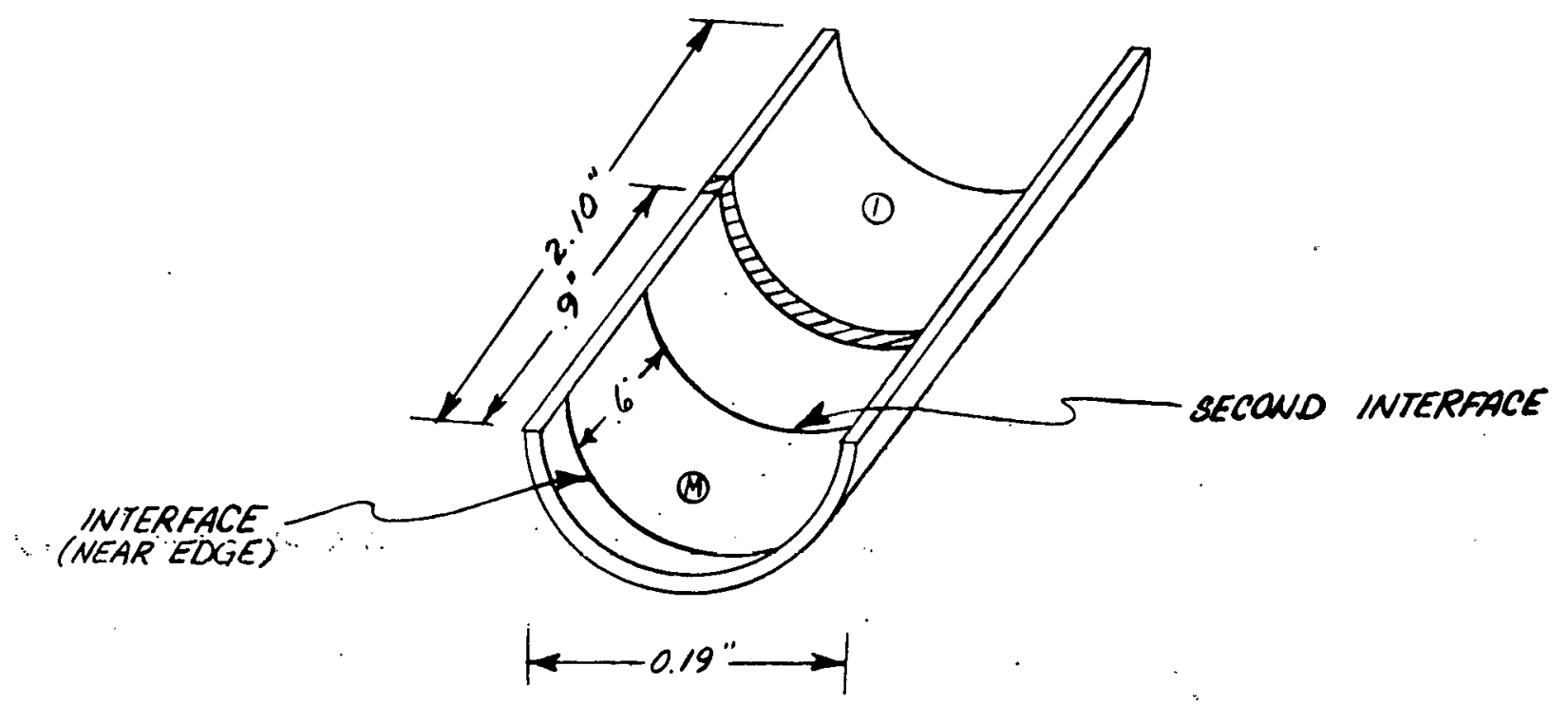

$R O D 0.0 .=0.255 \mathrm{IN}$

WI MICROAROBE SECTION

NOTE: CROSS-HATCH AREA REPRESENTS SECTION CUT.

Figure C-1. Sample 79-442-4-K 1, Sìt Clad Retainer Section 


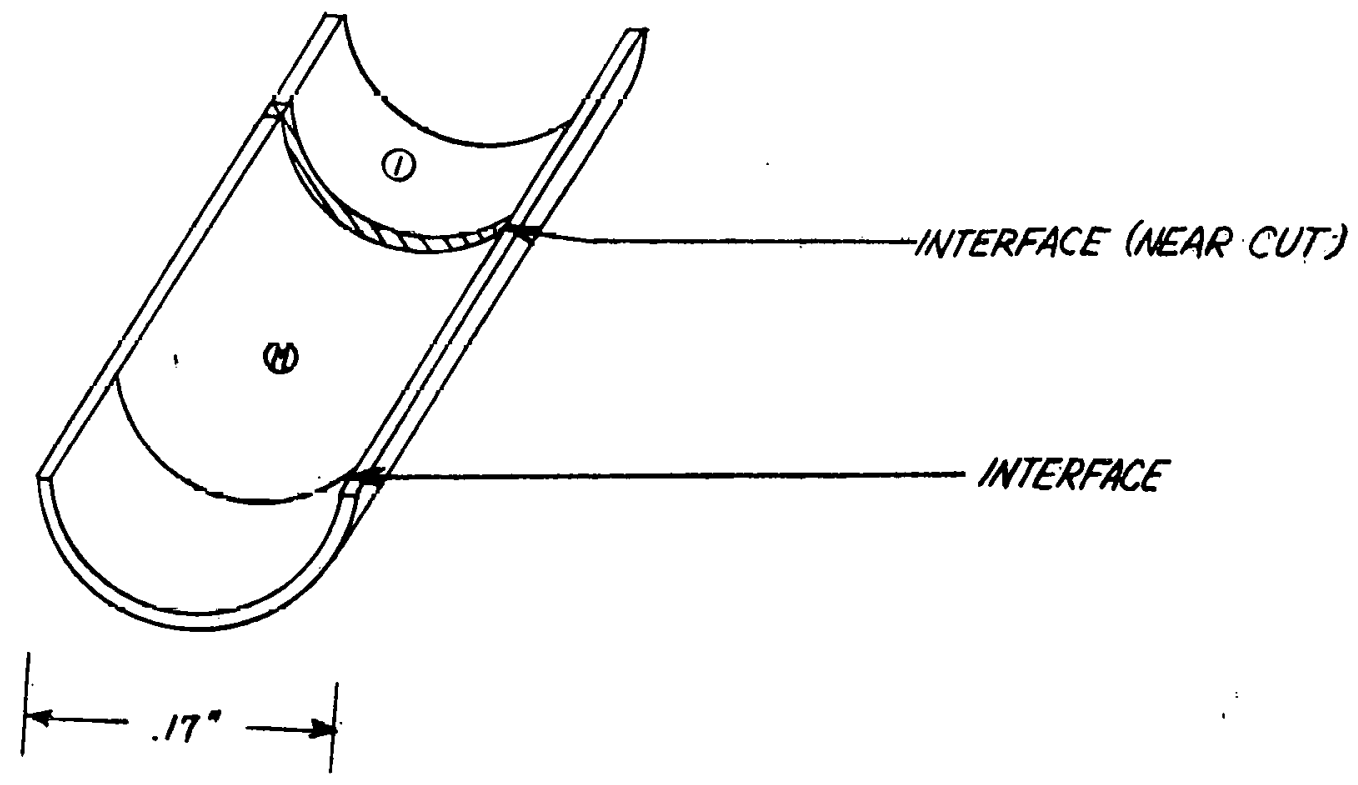

ROO 0.D. $=0.253 \mathrm{~N}$

Q MICAOPROBE SECTION

NOTE: CMUSSHATCH AREA REANOSENTS SECTION CUT.

Figure C-2. Sample 79-478-1 -2C-K 1, Slit Clad Retainer Section

C.8 


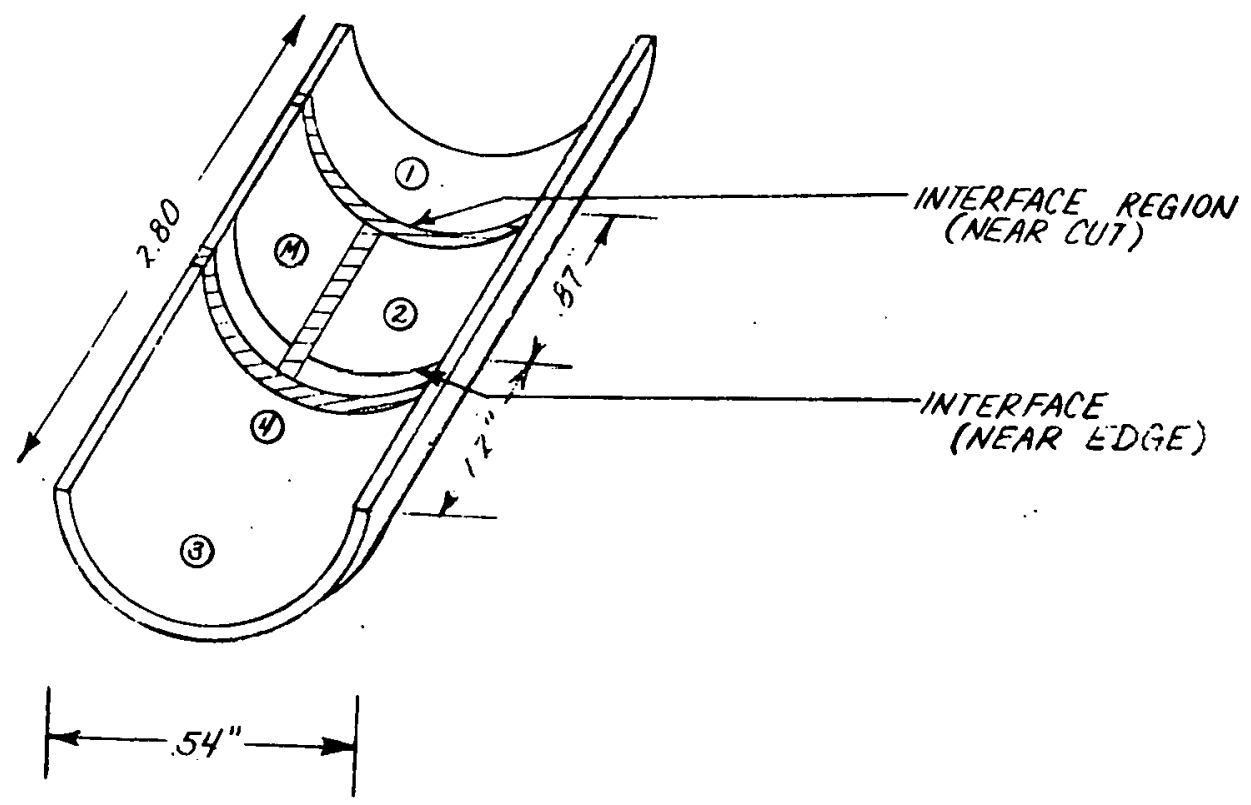

ROD O.D. $=0.613 \mathrm{IN}$

(D) MICROPROBE SECTION

NOTE: CROSS HATCH AREA REPRESENTS SECTION CUT.

Figure C-3. Sample 79-576-A 1 l-K 1, Slit Clad Retainer Section 


$$
.53 " 0.0
$$

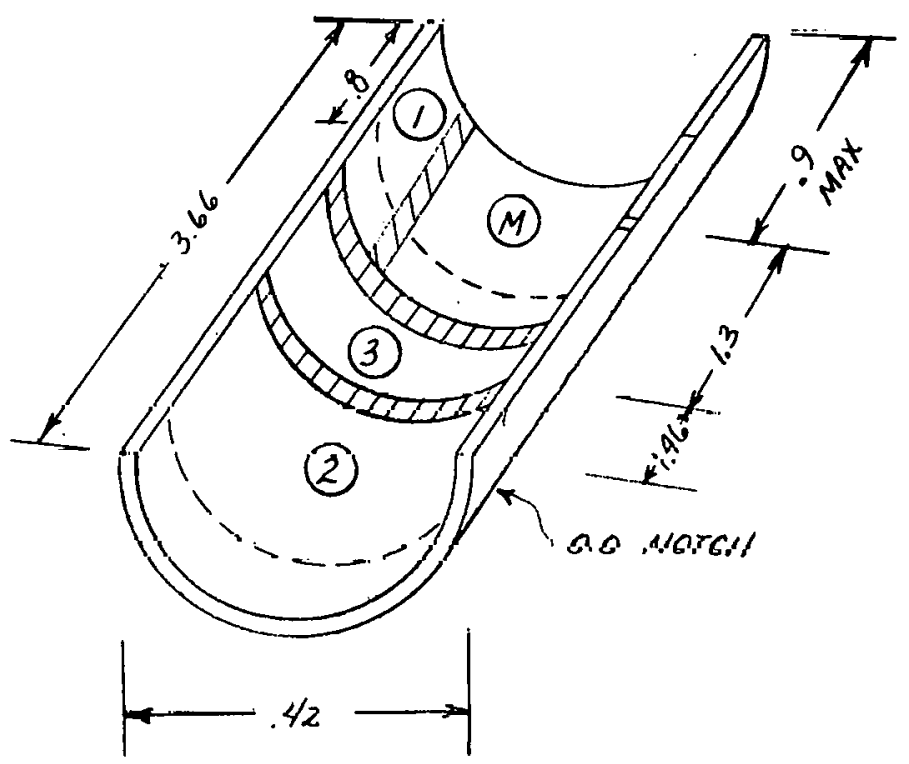

(17) MICROPROBE SAMPLE

$$
\begin{aligned}
\text { NOTE: } & \text { DOTTED LINE INDICATES } \\
& \text { PELLET-TO-PELLET INTERFACE }
\end{aligned}
$$




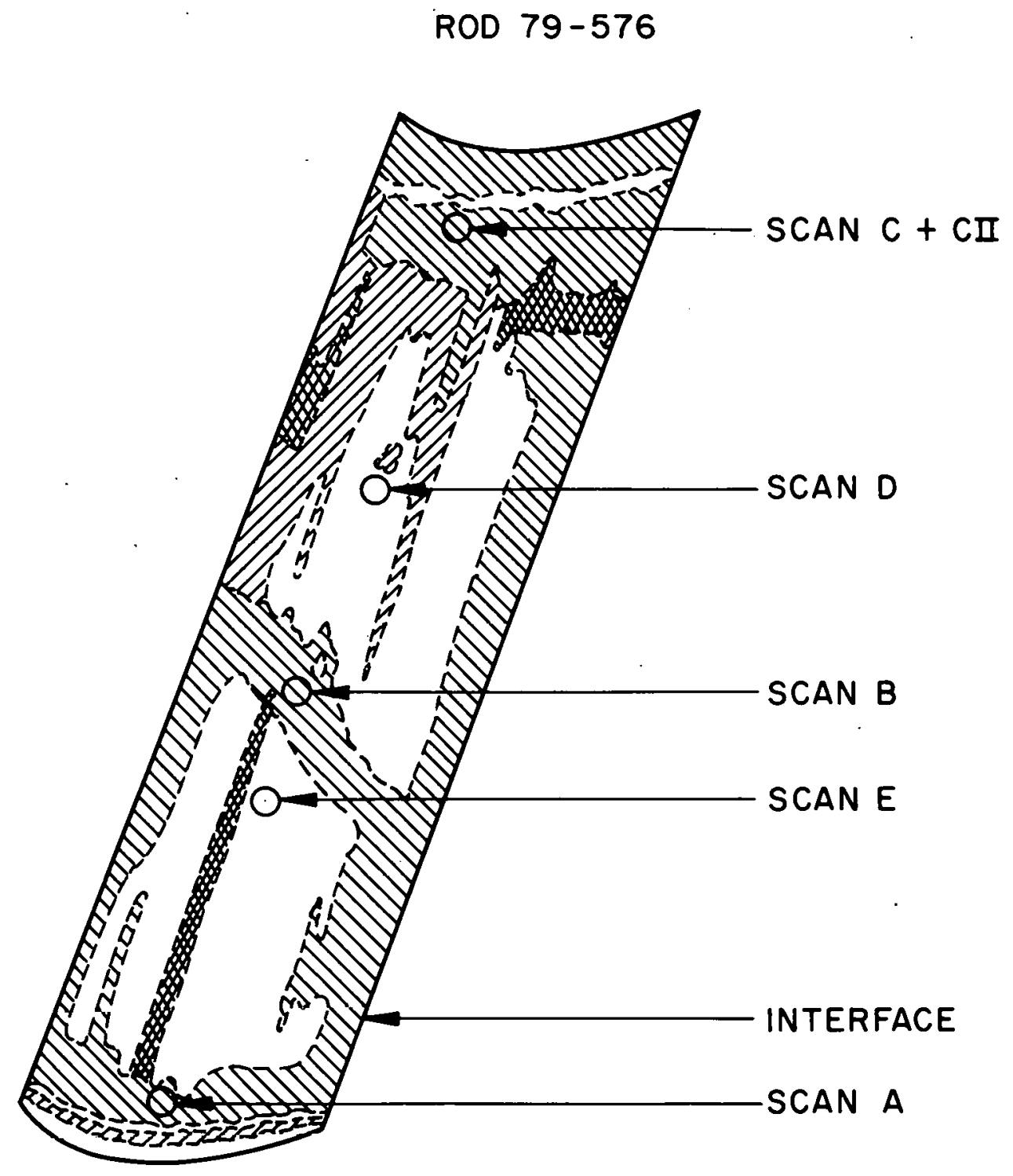

NOTE: CROSS-HATCHED AREAS DESIGNATE RELATIVE OXIDE DARKNESS (FROM VISUAL EXAMINATION)

Figure C-5. Approximate Areags Of Wavelength Scans 


\begin{tabular}{|c|c|c|c|c|c|}
\hline \multirow[b]{2}{*}{$\begin{array}{l}\text { Sample } \\
\text { Rod }\end{array}$} & \multirow{2}{*}{$\begin{array}{c}\text { Total } \\
\text { Depletion } \\
\left(10^{20} f / c c\right) \\
\end{array}$} & \multicolumn{3}{|c|}{$\begin{array}{l}\text { Radiochemistry } \\
\text { Recults } \\
\end{array}$} & \multirow[b]{2}{*}{ Summary of Microprobe Results } \\
\hline & & $\begin{array}{l}\text { Exposire } \\
\text { (EFPH) } \\
\end{array}$ & $\begin{array}{c}\text { Iodine } \\
\left(\mathrm{mg} / \mathrm{dm}^{2}\right) \\
\end{array}$ & $\begin{array}{l}\text { Cesium } \\
\left(\underline{m g} / \mathrm{dm}^{2}\right)\end{array}$ & \\
\hline $79-506$ & 4.8 & 12.080 & $\begin{array}{l}0.59 \\
(0.150)^{2}\end{array}$ & 5.81 & $\begin{array}{l}\text { Heavy concentration of :odine, cesium, tellurium and mercury at } \\
\text { the pellet interface reg:on. In:erface region also shows lower urani- } \\
\text { um and thorium levels :han other areas of the sample. }\end{array}$ \\
\hline $79-478$ & 11.7 & 11,020 & $\begin{array}{l}0.038 \\
0.07^{3} \\
(0.706)^{2}\end{array}$ & 3.15 & $\begin{array}{l}\text { No detectable iodine ol cesium above background levels an ywhere } \\
\text { on the sample }\end{array}$ \\
\hline $79-442$ & 10.3 & 8,540 & $\begin{array}{l}0.041 \\
0.21^{3} \\
(0.787)^{2}\end{array}$ & 0.82 & $\begin{array}{l}\text { Small amounts of cesium in one of two pellet interface regions } \\
\text { examined, but no iodine }\end{array}$ \\
\hline $79-576$ & 6.48 & 18,170 & $\begin{array}{c}0.015 \\
(0.26)^{2}\end{array}$ & 0.35 & $\begin{array}{l}\text { Distinct cesium in one or two of the pellet interface regions exam- } \\
\text { ined, but no iodine. This inte:face region shows lower uranium and } \\
\text { thorium levels than other areas of the sample. }\end{array}$ \\
\hline
\end{tabular}

\footnotetext{
'Samples were in the immedia:e vicinity ef the microproje specimen, 28 sully containing partions of the same pellet interfaces about 60 degrees apart.
}

${ }^{2}$ lodine values in parentheses are ca.culated from the LWBR design basis model

3epeated analysis with adjacent sa mple and "improved" analytical procedure. 
TABLE C-2. QUALITATIVE ANALYSIS OF 79-506

Element Detected

Region 1

Pellet-to-Pellet Interface

Surface

$\mathrm{U}$
$\mathrm{Th}$
$\mathrm{Te}$
$\mathrm{Cs}$
$\mathrm{I}$
$\mathrm{Ba}$
$\mathrm{Sn}$
$\mathrm{Si}$
$\mathrm{Zr}$
$\mathrm{Hg}$
$\mathrm{Mo}$
$\mathrm{Cl}$
$\mathrm{S}$

Region 2

Adjacent

Surface-to-Interface

$\mathrm{U}$

Th

$\mathrm{Te}$

Cs

I

$\mathrm{Ba}$

Sn

$\mathrm{Si}$

$\mathrm{Zr}$

$\mathrm{Hg}$

Mo

$\mathrm{Cl}$
Region 3

Interface-Free

Surface

$\mathrm{U}$

Th

$\mathrm{Te}$

Cs

I

Sn

$\mathrm{Si}$

$\mathrm{Zr}$

$\mathrm{S}$ 
TABLE C-3. QUALITATIVE ANALYSIS OF 79-442, 79-478, 79-576

\section{Area}

Elements Identified

Rod 79-442

Irregular End of Section

Opposite End of Section

Mid-Length of Section

Mid-point Between 2 and 3

Mid-point Between 2 and 3

Rod 79.478

End $\bar{A}$

End B

Center

Suspected Interfáce

Away from Interface

Rod 79.576

Mrca A

B

C

CII

D

E
$\mathrm{Th}, \mathrm{U}, \mathrm{Si}, \mathrm{Te}$

Th, U, Si, Cs, Ca, Ba, Rb, S

Th, U, Gi, Cs, Te

Th, U, Mo, Si, Cs, Te

$\mathrm{Th}, \mathrm{U}, \mathrm{Si}, \mathrm{Cs}, \mathrm{Te}$

Th, UI, Te, Mo, Cs

Th, U, Te, Mo, Cs

Th, U, Tө, Mo, Cs, Ca

Th, U, Te, Mn, S.s

Th, U, Mo, Cs

Th, U, Ca, S, Si

Th, U, S

$\mathrm{Th}, \mathrm{U}, \mathrm{Cs}, \mathrm{Ca}, \mathrm{S}, \mathrm{Si}, \mathrm{Ti}$

Th, U, Cs, S

Th, U, Cs, S, Si

Th, U, S, Si

The approximate locations of the Rod 79-576 analytical areas are shown in Figure 5. 

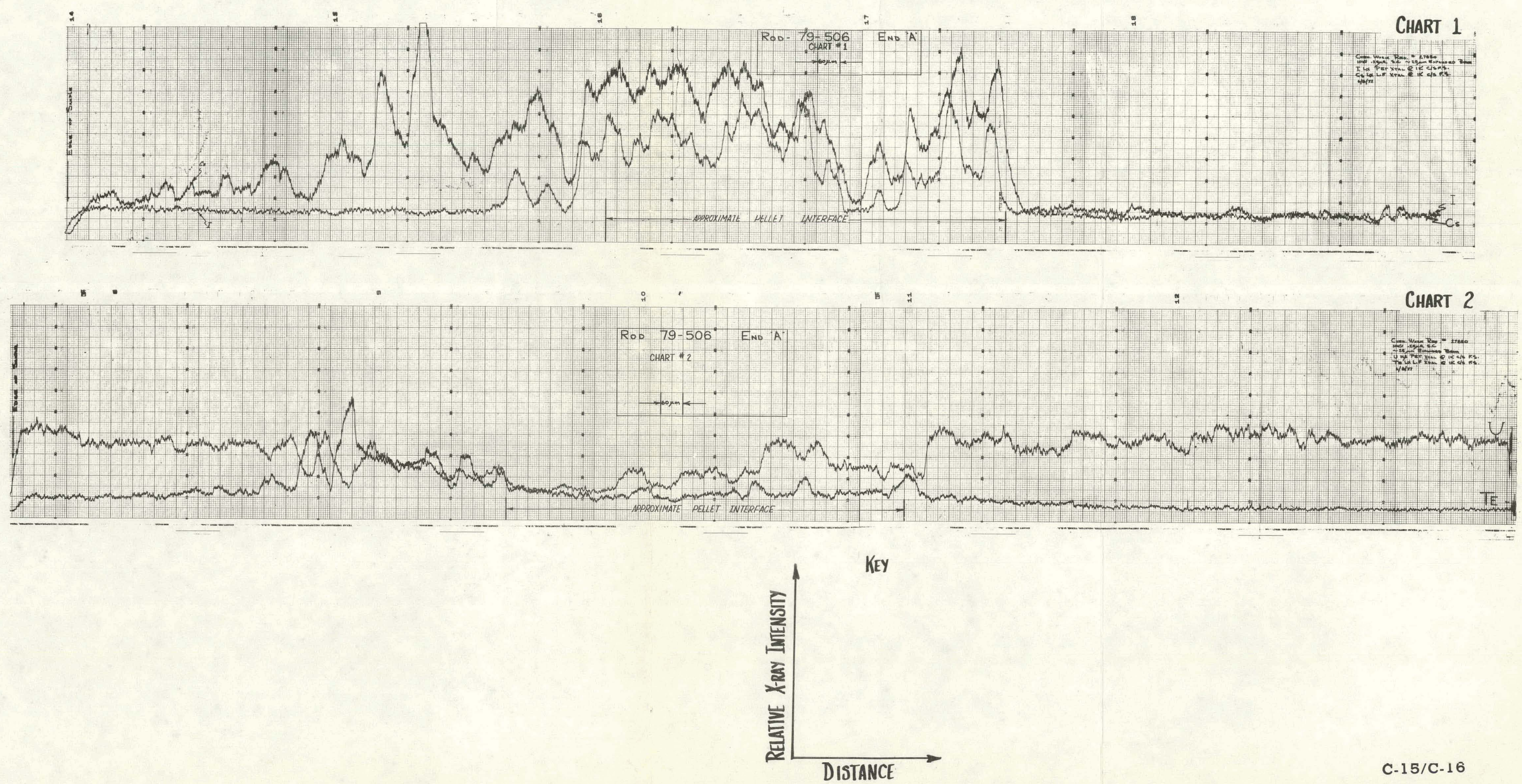



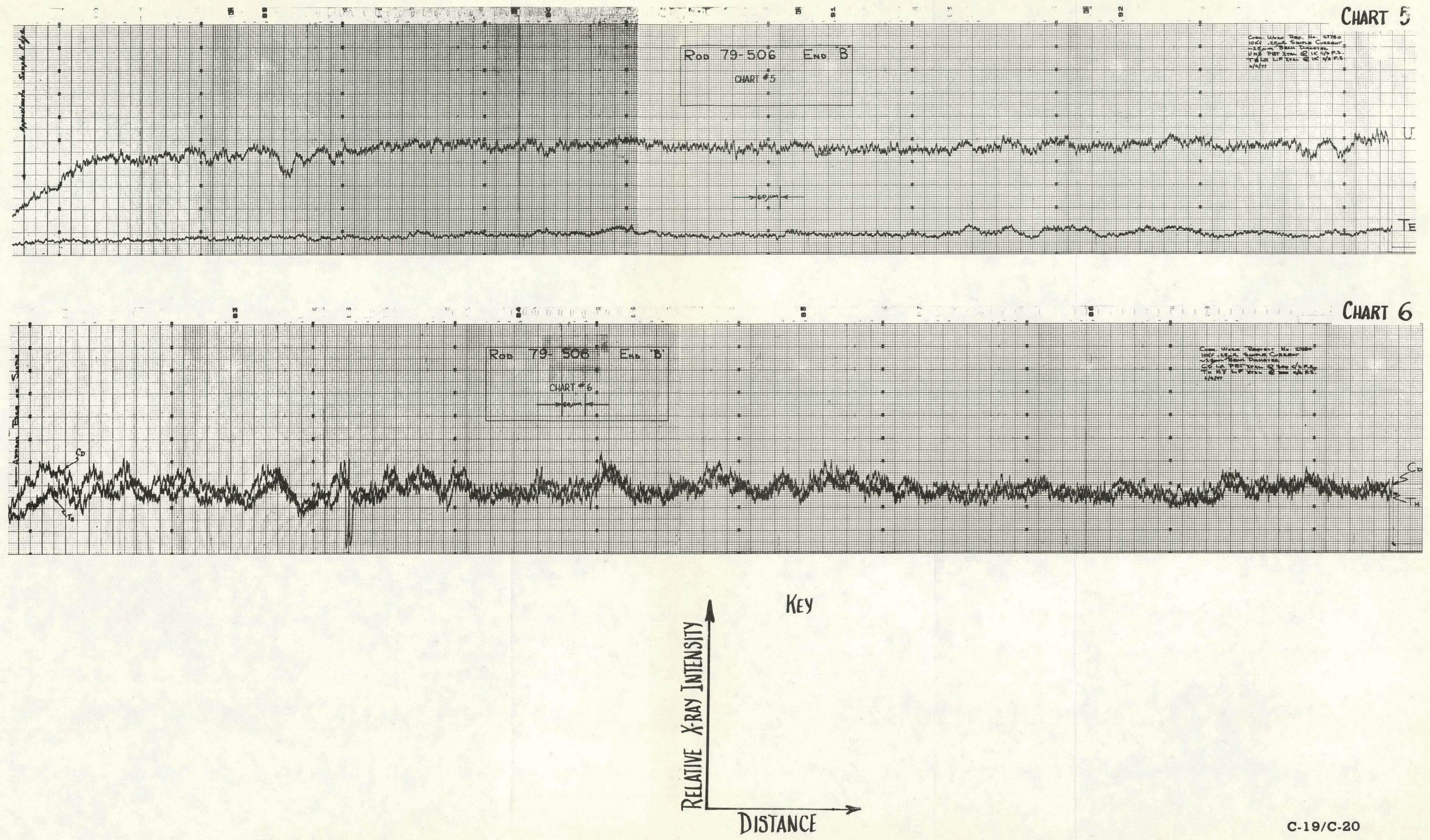


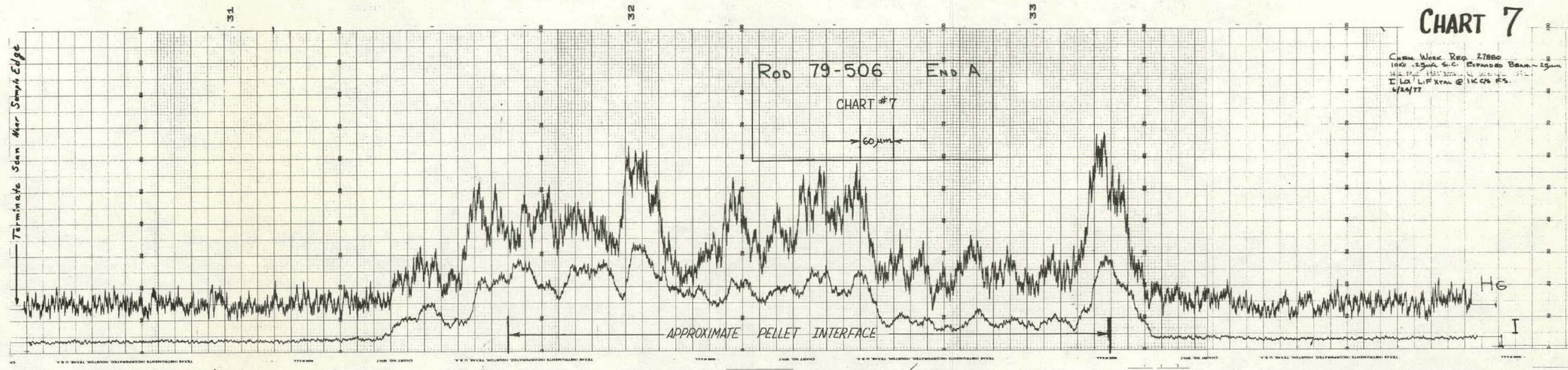

- ChART 8
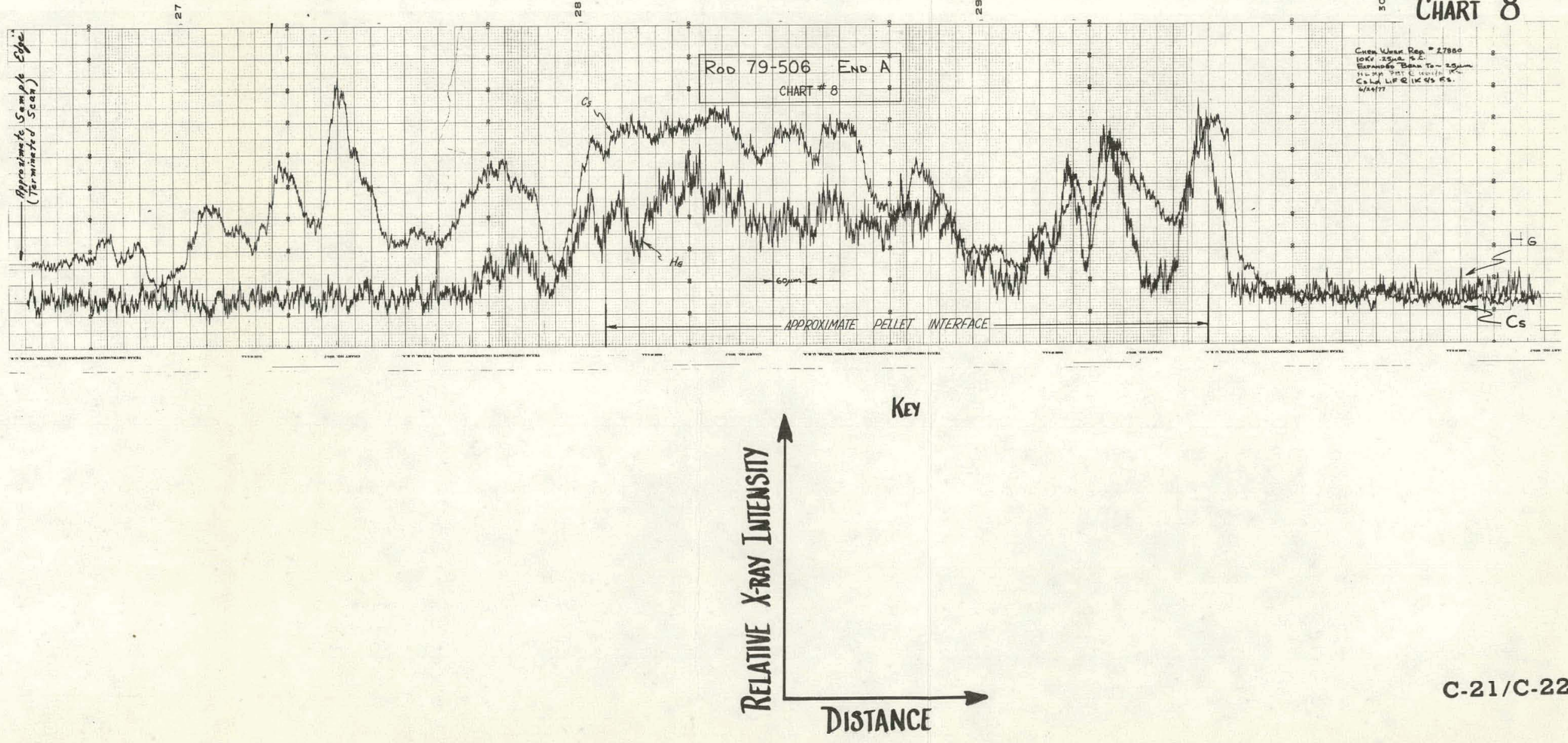